\title{
Experimental metrics for identifying origins of combustion variability during spark-assisted compression ignition
}

\author{
D L Reuss ${ }^{1 *}$, T-W Kuo ${ }^{1}$, G Silvas ${ }^{1}$, V Natarajan ${ }^{2}$, and V Sick ${ }^{2}$ \\ ${ }^{1}$ Powertrain Systems Research Laboratory, General Motors R \& D Center, Warren, Michigan, USA \\ ${ }^{2}$ University of Michigan, Ann Arbor, Michigan, USA
}

The manuscript was accepted after revision for publication on 2 June 2008.

DOI: $10.1243 / 14680874 J E R 01108$

\begin{abstract}
Spark-assisted compression ignition, SACI, can be used to control the combustion phasing of compression-ignition gasoline engines. However, implementation of this technique can be confounded by cyclic variability. The purpose of this paper is to define experimental metrics that describe the SACI process and to demonstrate the use of these metrics for identifying the source(s) of cyclic variability during the SACI process.

This study focused on a light load condition ( $7 \mathrm{mg} / \mathrm{cycle}, 200 \mathrm{kPa}$ i.m.e.p.), where spray-guided direct fuel injection with spark ignition and an exhaust-rebreathing strategy was employed to achieve flame propagation, which led to compression ignition. This study employed a combination of measurements including pressure-based heat-release analysis, spark-discharge voltage/current measurements, and cycle-resolved combustion imaging. Based on these measurements, four distinct combustion periods were identified; namely, the spark discharge, the early kernel growth (EKG), flame propagation, and the compression ignition periods. Metrics were defined to characterize each period and used to identify the contribution of each period to the cyclic variability of the main heat release. For the light load condition studied here, the EKG period had the largest effect on the crank angle (CA) position of 50 per cent mass burned, CA50. The spark-discharge event may affect CA50 indirectly through its influence on EKG. However, this could not be definitively assessed here since the camera was incapable of recording both the spark-discharge event and the flame images during cycles of the same tests.
\end{abstract}

Keywords: homogeneous charge compression ignition (HCCI) engine, spark-assisted compression ignition, spark-assisted HCCI, cyclic variability

\section{INTRODUCTION}

Ignition and the burning rate of homogeneous charge compression ignition (HCCI), engines are controlled by chemical reaction rates; therefore, phasing ${ }^{\dagger}$ is dominated by the in-cylinder temperature and composition. In practical gasoline compression ignition (CI) engines, the in-cylinder mixture temperature varies from cylinder to cylinder and during transients due to variations in

*Corresponding author: General Motors R\&D, MS 480-106-252, 30500 Mound Road, Warren, MI 48090-9055, USA. email: david. l.reuss@gm.com

${ }^{\dagger}$ Here the combustion phasing is defined as the crank angle of 50 per cent mass fraction burned, CA50. intake-charge temperature, residual-charge temperature and amount, and wall temperatures. Consequently, control methodologies are required $[\mathbf{1}, \mathbf{2}]$.

Spark-assisted compression ignition (SACI) combustion, is one method to achieve control of HCCI in gasoline engines. Where several studies have focused on higher loads, especially transition from HCCI to spark ignition (SI) operation [3-9], this study focuses on phasing control at low load. As implemented with stratified-charge direct-injection in this study, SACI is achieved by injecting a portion of the fuel early in the intake stroke to create a nearly homogeneous fuel, air, and residual mixture; then a second injection, late in the compression stroke, creates a stratified charge that is spark ignited. Thus, SACI combustion begins as flame propagation in a 
stratified-charge spark-ignited direct-injection engine configuration that increases the unburned fuelair charge to pressures and temperatures above those that would otherwise be achieved with the piston compression alone. This causes CI combustion of the unburned gas to occur at an earlier CA than would occur with piston compression alone, analogous to traditional SI knock but with a controlled heat-release rate.

SACI combustion suffers from high cycle-to-cycle variability as demonstrated by Perrson et al. [7], which potentially has the same causes of variability present in both conventional SI and stratifiedcharge/spark-ignited direct-injected (SC/SIDI), engines. Cyclic variability of combustion phasing in homogeneous SI engines has been traced to the spark discharge event itself; it is dominated by the flow-velocity variability, as long as the dilution level (air, residual, or EGR) is low enough to support robust combustion [10]. However, SC/SIDI cyclic variability is also increased by fuel stratification and flow induced by the injection event. In principle, SACI also experiences variability during the CI combustion; however, it will be shown here that the CI duration is small and actually decreases the variability resulting from the ignition and flamepropagation phases of the combustion process.

The purpose of this study is to establish measured metrics that characterize the SACI combustion process and identify the influence of each period on CI-phasing variability; cycle-to-cycle variability of cylinder mass and composition are not addressed here. A single light-load engine-operating condition is used for this demonstration $(7 \mathrm{mg} /$ cycle fuel, $200 \mathrm{kPa}$ i.m.e.p.). Four combustion periods are defined during SACI, as illustrated in Fig. 1, namely, the spark discharge, the EKG, flame propagation, and the CI periods. This paper describes the characterization and quantification of SACI combustion and its cyclic variability achieved using

(a) steady state emissions;

(b) pressure-based heat release;

(c) spark discharge voltage and current measurements;

(d) imaging of the spark and combustion process.

This manuscript describes the engine and combustion characterization in the order just enumerated. This is followed by a discussion identifying the causes of cyclic variability by correlating the ignition and flame parameters against each other and CA50.

\section{BACKGROUND}

This background contains two sections. Section 2.1 provides a description of the four periods of SACI already defined based on the results of this study; this summary is provided prior to the results in order to provide the reader with a perspective for the details that follow. Section 2.2 describes the cyclic variability of SACI combustion, which is the motivation for this study.

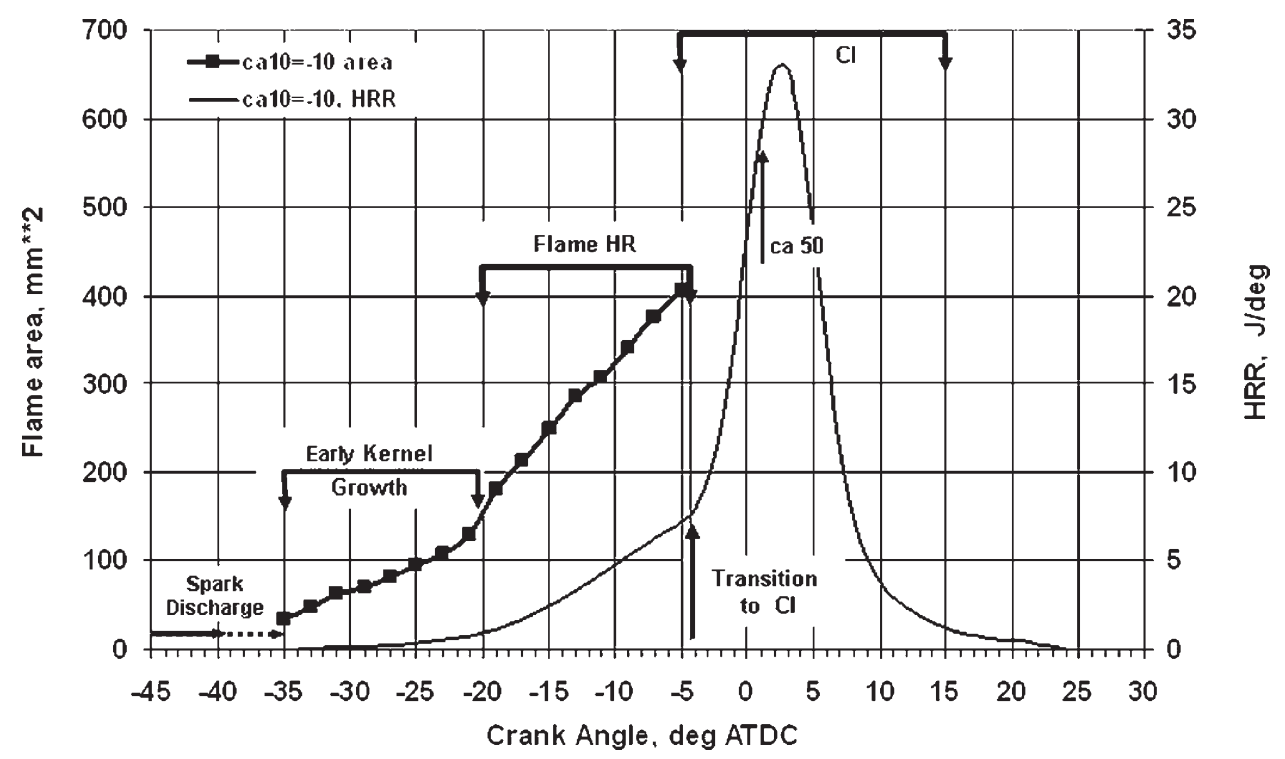

Fig. 1 Definition of the four SACI combustion periods using the imaged flame area and heatrelease rate, HRR, for ensemble-averaged cycles conditionally sampled on CA50 = 2 ATDC 


\subsection{The four periods of SACI combustion}

This study focused on a light-load condition, where spray-guided direct fuel injection was required to achieve flame propagation. The four combustion periods are defined based on the spark current, measured flame areas, and heat release rate, HRR. These four periods are illustrated in Fig. 1 as the spark discharge, the early kernel growth (EKG), the flame propagation, and the CI combustion periods. The beginning of the spark discharge is the spark set point, CASpk. The end of the spark ignition event, EOSpk, is defined as time when the spark-discharge current returns to zero and by the definition here is equal to the beginning of the EKG event.

Conceptually, EKG is the period after the spark discharge where a small reaction kernel exists, but with weak chemiluminescence, slow area growth, and too little heat release to be reliably measured with pressure-based heat-release analysis. This is a light load phenomenon where the flame is too weak to propagate strongly. Eventually heat release proceeds at a more rapid rate, presumably because the early kernel

(a) encounters a more favourable air-fuel ratio;

(b) encounters higher temperatures due to compression; or

(c) CI combustion occurs before the kernel becomes robust.

The end of the early-kernel growth, EOEkg, is defined as the crank angle where the second derivative of the flame area, $\mathrm{d}^{2} \mathrm{~A}_{\mathrm{flm}} / \mathrm{dCA}^{2}$, is maximum, and is defined here as being equal to the beginning of the flame propagation. This definition of the EKG period is conceptually similar to the model of Abraham et al. [11], which describes an ignition kernel in a conventional homogeneous SI engine that first grows slowly on a laminar-flame timescale and then transitions to rapid growth on a turbulent-flame timescale.

The 'flame' is defined here as the period where the chemiluminescence becomes more intense, area growth faster than during EKG, and the heat release is measurable (Fig. 1). 'Flame' here should be interpreted as a convenient label rather than taken literally, since the measured heat release may be a combination of $\mathrm{CI}$ and true flame* combustion,

*Here a 'true' flame is considered to have the properties a deflagration wave with a propagation rate through a partially premixed stratified fuel-air mixture that is controlled by a convective-diffusive balance. which the measurements here cannot discriminate. This interpretation of the combustion is analogous to the initial slow heat release, ISHR, defined by Perrson et al. [7], which was presumed to be a flame also. The end of the flame propagation is defined to be the CA where the combustion transitions to CI combustion, CATrans. CI heat release rates occur over chemical-reaction timescales and are faster than HRRs of turbulent flame propagation. Thus, CATrans is considered to be the time when the overall HRR changes from the slower 'flame' rate to the faster CI rate, here measured as the point where the second derivative of the $\mathrm{HRR}, \mathrm{d}^{2} \mathrm{HRR} / \mathrm{dCA}^{2}$, is maximum as in [7].

The EKG and flame period definitions are not based on fundamental definitions of deflagration waves, but rather, are based on the observed rate changes. These parameters become useful engineering metrics that will be used here to define the series of event(s) and to identify which, if any, of the events dominate cyclic variability of the CI combustion phasing.

\subsection{Cyclic variability of SACI combustion}

The light-load engine-operating condition studied here was fuelled with $7 \mathrm{mg} /$ cycle gasoline. For pure $\mathrm{CI}$ operation all $7 \mathrm{mg}$ of the fuel was injected at -330 ATDC. ${ }^{\dagger}$ The water temperature, intake temperatures, and injection strategies used for SACI (Table 1) and shown graphically in Fig. 2 were derived as follows. Firstly the engine was operated at the pure CI condition with a hot wall $\left(90^{\circ} \mathrm{C}\right.$ cooling water to the head and cylinder, $\mathrm{T}_{\text {wall }}$, ) and the intake temperature, $\mathrm{T}_{\text {intk }}$, sufficiently hot $\left(205^{\circ} \mathrm{C}\right)$ to yield a location of peak pressure, LPP, equal to 9 ATDC. Next, the water temperature was reduced to $65^{\circ} \mathrm{C}$, (retaining EOI $=-330$ and $\mathrm{T}_{\text {intk }}=205^{\circ} \mathrm{C}$ ) to retard the LPP to 12.5 ATDC. SACI was then used (retaining $\mathrm{T}_{\text {intk }}=205^{\circ} \mathrm{C}$ and $\mathrm{T}_{\text {wall }}=65^{\circ} \mathrm{C}$ ) to regain 9 ATDC LPP, where $4 \mathrm{mg} /$ cycle injected at EOI $=-330,3 \mathrm{mg} /$ cycle injected at -45 ATDC, and spark ignition advanced to -45 ATDC (dotted line, Fig. 2). This was the minimum second-injection fuelling rate required to readvance the LPP, and thereby overcome the enthalpy deficit created by the cold coolant.

The difference between the CI and SACI HRRs and their cyclic variability are shown in Fig. 3. Figure 3(a) shows the ensemble-averaged HRRs, corresponding to three extreme conditions indicated by the large

${ }^{\dagger}$ ATDC indicates crank angle degrees after top dead centre of the compression stroke. 
Table 1 Engine hardware and operating parameters

\begin{tabular}{|c|c|c|c|c|c|}
\hline Bore $\times$ stroke $(\mathrm{mm})$ & $86 \times 94.6$ & Speed & $1000 \mathrm{r} / \mathrm{min}$ & & \\
\hline Compression ratio & $11: 1$ & Intake map & $100.5 \mathrm{kPa}$ & & \\
\hline EVO1, $10 \mathrm{~mm}$ & 138 ATDC & Exhaust map & $101.5 \mathrm{kPa}$ & & \\
\hline EVC1 & 373 ATDC & $\mathrm{A} / \mathrm{F}$ & $20: 1$ & & \\
\hline $\mathrm{EVO} 2,4 \mathrm{~mm}$ & 378 ATDC & & CI & CI & SACI \\
\hline EVC2 & 521 ATDC & $\mathrm{T}_{\text {wall }}(\mathrm{C})$ & 90 & 65 & 65 \\
\hline $\mathrm{IVO}, 4 \mathrm{~mm}$ & 297 ATDC & $\mathrm{T}_{\text {intake }}(\mathrm{C})$ & 205 & 205 & 205 \\
\hline IVC & 565 ATDC & $\mathrm{T}_{\text {exh port }}(\mathrm{C})$ & 328 & 338 & 332 \\
\hline Piston bowl & VVA3 & $\mathrm{T}_{\mathrm{IVC}}(\mathrm{C})$ & 264 & 265 & 267 \\
\hline Fuel & Indolene $[22]$ & Injection timing, EOI ATDC & -330 & -330 & $-330 /-45$ \\
\hline P fuel & $11 \mathrm{MPa}$ & Fuelling rate, mg/cycle & 7 & 7 & $4 / 3$ \\
\hline Spark plugs & $\begin{array}{l}\text { Traditional and double pin, } \\
9 \mathrm{~mm} \text { long centre electrode }\end{array}$ & Spark timing, ATDC & n.a & n.a & -45 \\
\hline
\end{tabular}

circles in Fig. 2. Figure 3(a) reveals that the peak, average HRR of the SACI combustion (black dotted) is phased the same as the original hot-coolant CI, which was expected based on LPP in Fig. 2. The conditionally averaged HRRs of the SACI cycles in Fig. 3(a) provide insight into the nature of the combustion. The curves in Fig. 3(a) are ensemble averages of the individual-cycle HRR(CA) curves conditionally sampled on those cycles for which the CA at 10 per cent mass-burned fractions, CA10, occurred at -10.6 and $-2.6 \pm 0.5$ ATDC (red and blue dotted). Consider first the early burning cycles CA10 $=-10.6$; these early SACI cycles have nearly the same phasing as the hot wall $\left(90^{\circ} \mathrm{C}\right) \mathrm{CI}$ operation but with more heat release between -20 and -5 CA (albeit slow compared to the primary heat release), which here is attributed to flame propagation. The late CA10 cycles are phased later than the pure CI at the same fuelling rate and coolant temperature. These conditionally averaged HRR curves demonstrate that the ensemble average of all SACI cycles is a poor representation of either the

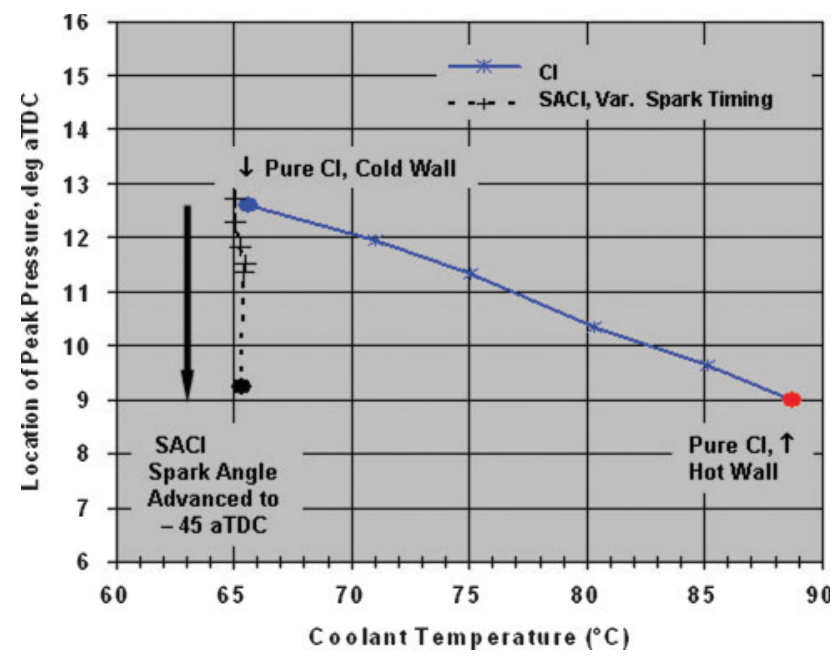

Fig. 2 Combustion-pressure phasing used to establish the SACI operating condition early or late SACI cycles, implying high cyclic variability. The cyclic variability is shown succinctly in Fig. 3(b), where both CA10 and CA50 of SACI have five times the range compared to that of either hot or cold coolant CI. The phasing variations in Fig. 3(b) result in the i.m.e.p. variations shown in Fig. 3(c), which directly affect the noise, vibration, and harshness engine operation. Revealing the causes of this variability was the motivation for this study.

Figure 4(a) shows i.m.e.p. versus the amount of fuel burned during a given cycle; this demonstrates that i.m.e.p. variability is directly related to the amount of fuel burned during a given cycle. Combining the results of Fig. 4(a) with Fig. 3(c), Fig. 4(b) shows the relationship between mass burned per cycle and CA50, and implies that early combustion phasing is required to burn more of the fuel or vice versa. The plot of CATrans and CA10 in Fig. 4(c) demonstrates that the transition to CI at this operating condition always occurs after 10 per cent of the mass has burned, CA10, and that the phase variability of the main combustion (CI) is established prior to both CATrans and CA10. Thus, to determine the cause of the cyclic variability in combustion phasing, it is necessary to investigate variability prior to CA10. Since accurate heat release calculations from the cylinder pressure are notoriously difficult prior to CA10, the spark and imaging diagnostics were employed as described below.

\section{EXPERIMENTAL HARDWARE AND PROCEDURES}

The experiments herein required four recording systems and correlation of the data from each. Steady state engine-out emissions were recorded averaged over the duration of each 300-cycle test. Incylinder pressure was recorded once per CA for all 300 cycles and used for individual-cycle heat release analysis. Spark-discharge voltage and currents were 

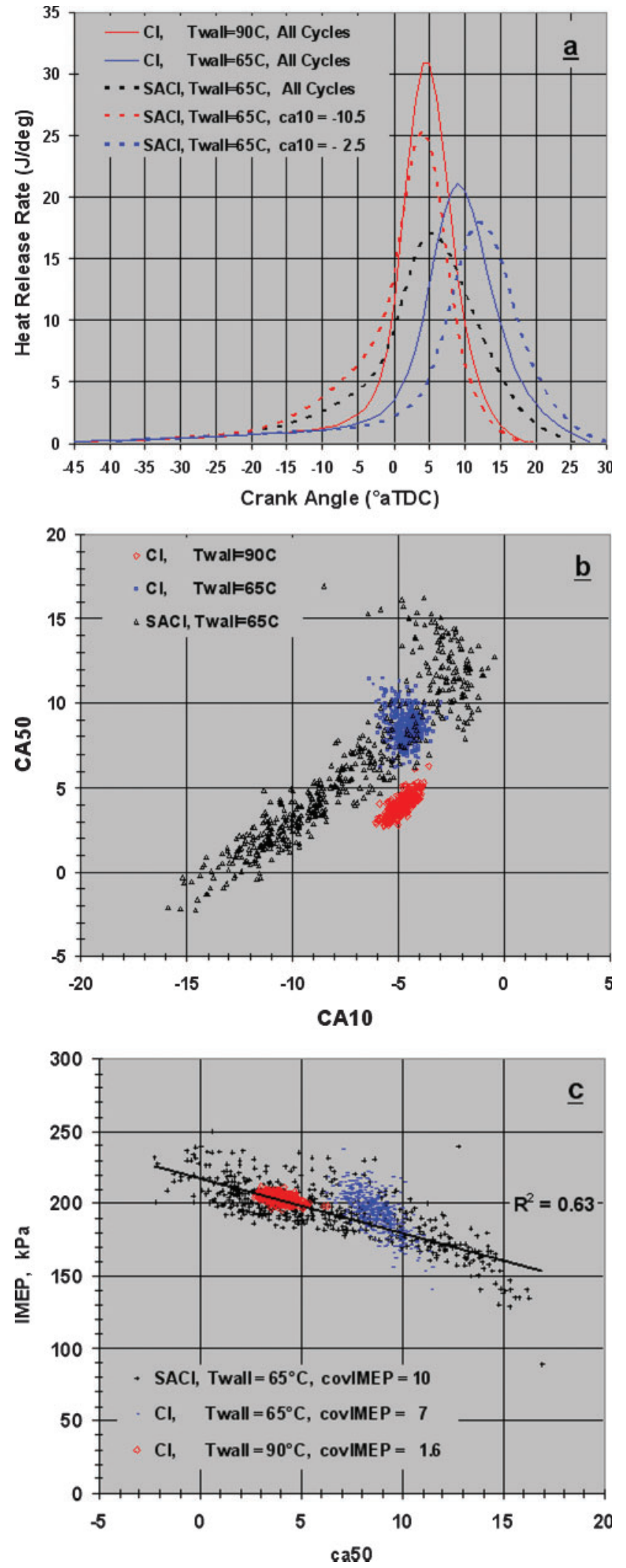

Fig. 3 Comparison of heat release parameters for the three operating conditions indicated by the large circles in Fig. 2
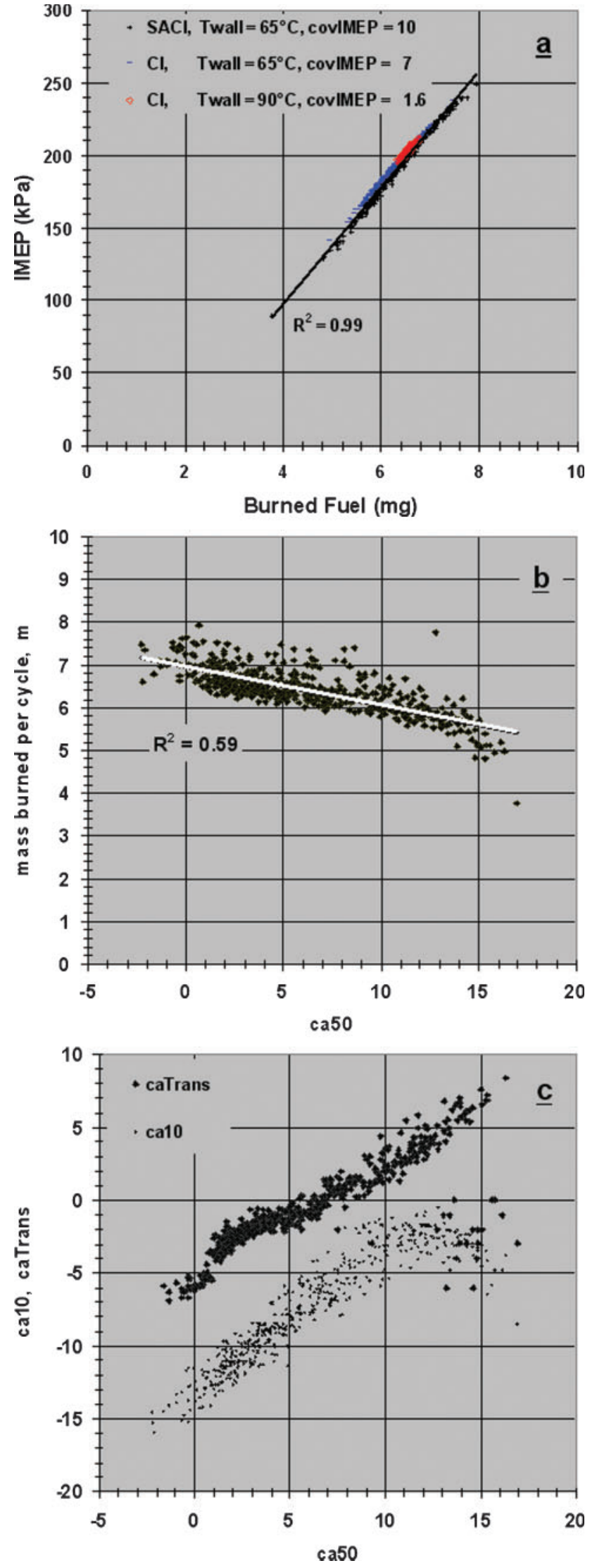

Fig. 4 Correlation of individual-cycle heat-release parameters 


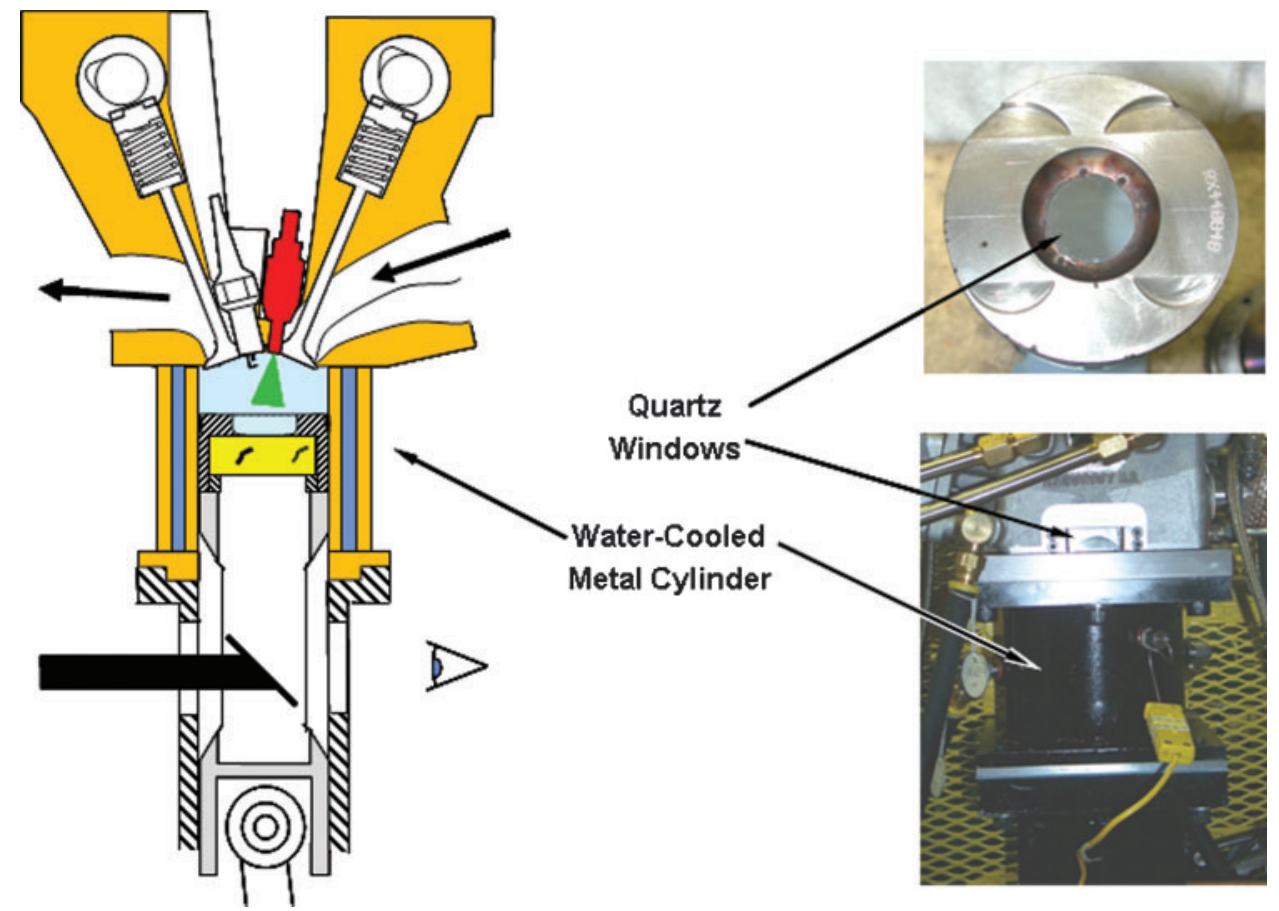

Fig. 5 Optical engine and piston configuration

recorded with a digital oscilloscope at $1 / \mu$ s intervals during the glow discharge of each engine cycle. Images of the spark-discharge plasma channel and the subsequent combustion were recorded using a high-speed framing camera. Images could be recorded only every third or fourth cycle. Therefore, six tests of 300 engine cycles/test were recorded at each operating condition to sample 480 imaged cycles with corresponding heat-release data. The equipment, procedures, and the measured parameters are given in this section.

\subsection{Engine configuration and operation}

The engine used in this study, illustrated in Fig. 5, is an optical single-cylinder SIDI engine with a circular piston bowl [12]. This is a four-valve pent-roof engine with centre injector and centre spark plug located in a spray-guided SIDI configuration (SG/ SIDI). The geometric characteristics and operating parameters are listed in Table 1. The photograph and schematic in Fig. 5 show one of the two windows at either end of the pent-roofed combustion chamber, a window in the piston bowl, and the extended Bowditch-type piston.

For the tests described in this paper, an all-steel piston top and a water-cooled chrome-plated steel cylinder were used. A single one-piece Rulon piston ring was used as suggested by Miles and Steeper [13] but with the addition of a felt oiler ring where the second compression ring would otherwise have been located. This ring arrangement provided blow-by that was less than 1 per cent of the trapped charge and allowed consistent steady state engine operation in excess of $3 \mathrm{~h}$.

CI combustion was achieved using an exhaustrebreathing strategy, where high in-cylinder gas temperatures are realized at intake-valve closing, (IVC), by reopening the exhaust valve during the intake stroke (Fig. 6). In these tests 60 per cent residual mass was realized. In addition, the intake

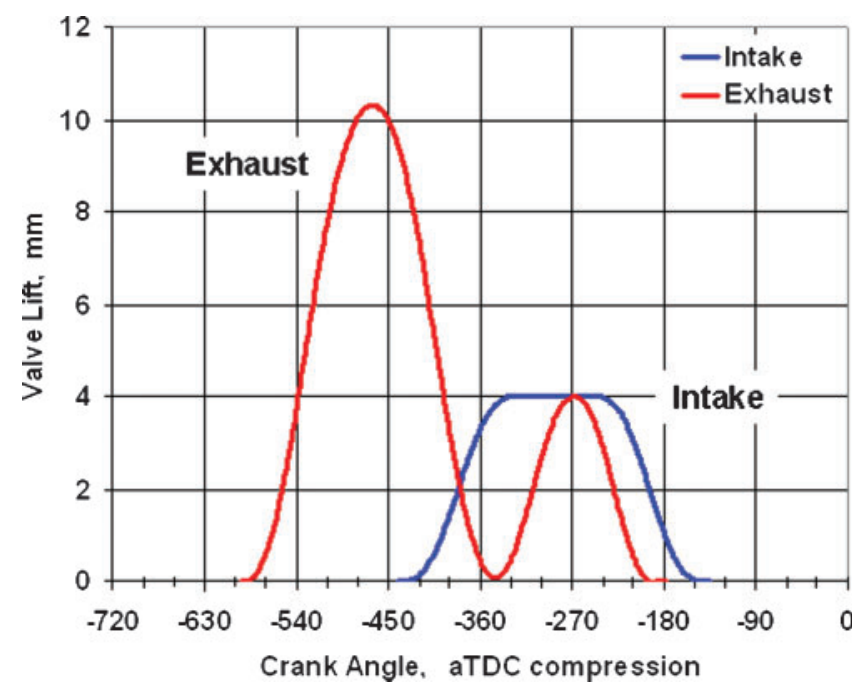

Fig. 6 Intake- and exhaust-cam profiles for rebreathing operation 

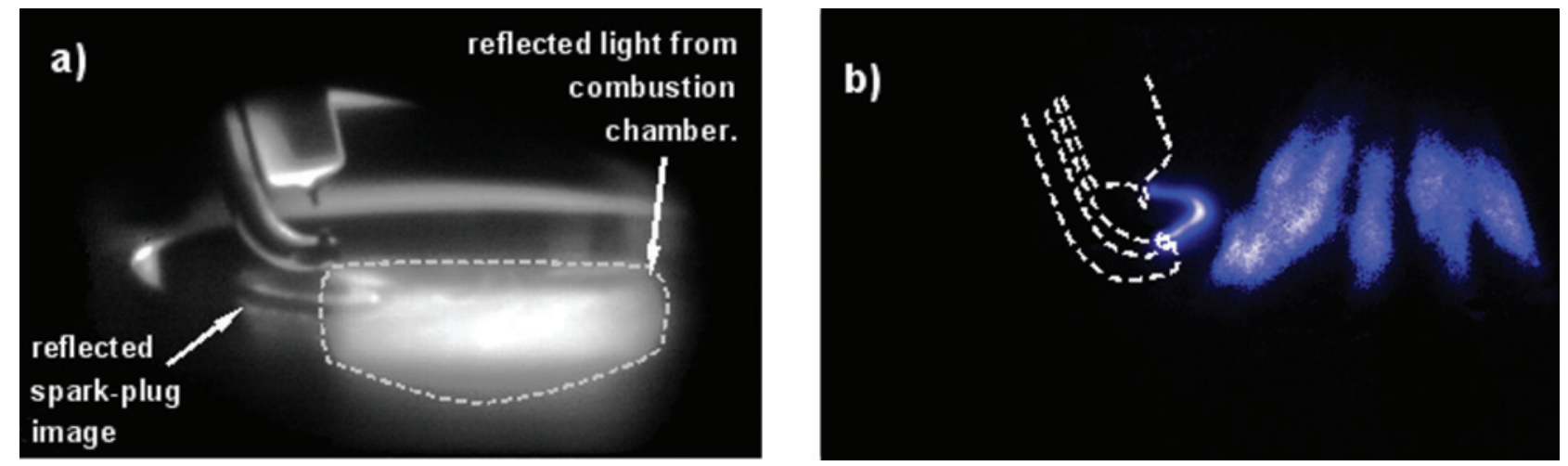

Fig. 7 Field of view (a) back lit and (b) back lit with spray and spark discharge

plenums and runners were heated to the desired intake temperature to minimize thermal gradients in the fresh charge. The exhaust runner and plenum were electrically heated to $400 \mathrm{C}$ to minimize heat loss from the burned gases during exhaust and reingestion.

An 8-hole, $60^{\circ}$ included cone angle (see Table 1) injector was used with one spray jet targeted at, but just below, the spark plug gap (Fig. 7(b)). A highenergy ignition system was used, which produced on average $67 \mathrm{~mJ}$ to the plug. Two different spark plugs were used here, both with a $9 \mathrm{~mm}$, centreelectrode reach. A spark plug with traditional flat electrodes was used in the initial tests; data from this spark plug is used in Figs 9 and 10 to demonstrate the correspondence between the imaging and electrical characteristics. A spark plug with small iridium pins on both the centre electrode and ground strap was used for all other tests presented here. Both are $5 \mathrm{k} \Omega$ resistive plugs and thus $52 \mathrm{~mJ}$ of the $67 \mathrm{~mJ}$ was delivered, on average, across the spark-plug gap.

\subsection{Pressure-based combustion analysis and emissions}

The cylinder pressure was measured with a Kistler 6125 piezoelectric transducer with a slotted flame arrestor and fitted through the water jacket into the ridge of the pent-roofed head. The pressure was recorded once per CA. The pressure-based combustion analysis (HRR versus CA and mass-burned fraction, (mbf), versus CA) was computed for the pressure record from each cycle and then averaged over all cycles, but modified for the CI and rebreathing operation. To compensate for the heatloss for the CI operation, the Woschni heat-loss correlation constant $\mathrm{C}_{2}$ was set to zero as per Chang [14], to suppress the pressure correction normally used for analysis of SI combustion with flame propagation. The heat-loss totalled over all cycles was adjusted to balance with the work plus fuel energy delivered over all cycles. The delivered fuel was measured with a positive-displacement meter to $0.1 \mathrm{mg} / \mathrm{cycle}$, and the average delivered fresh air measured with choked-flow orifices to 1 per cent. To compute the trapped-residual-mass fraction with the rebreathing cam, the volume of the fresh charge at IVC is computed assuming all of the delivered average fresh charge is trapped and at the average intake temperature and MAP. The remaining cylinder volume is assumed to be filled with residual that is at the same average temperature, pressure, and composition measured in the exhaust port. Since the exhaust temperature and composition are averaged over 300 cycles and the pressure of each cycle was pegged (in-cylinder piezoelectric pressure transducer readjusted to intake manifold absolute pressure to account for charge drift) at -180 ATDC compression, the only modelled cycle-to-cycle variations in the residual mass fraction are those due to differences in the pressure at IVC. Finally, the mbf computed by the heat release code is less than that indicated by the combustion efficiency from the exhaust emissions; the combustion efficiency is based on the delivered fuel whereas the final mass computed in the heat release is based on the trapped fuel (delivered plus rebreathed).

A standard engine-emissions bench was used for exhaust-gas measurements and analysed as per Stivender [15]. This provided the steady-state engine-out emissions averaged over the duration of the 300 cycle tests, including hydrocarbons, $\mathrm{O} 2, \mathrm{CO} 2$, $\mathrm{CO}, \mathrm{NO}_{x}$. The air-fuel ratio (AF), based on oxygen 
and carbon balance were computed. All three values of AF (based on emissions oxygen balance, emissions fuel balance, and the previously described measured fuel and air flowrates) were 20:1 and agreed to within a 0.5 ratio.

The single-cycle heat-release analysis was used to compute five one-per-cycle parameters for characterizing cyclic variability. In particular,

$\begin{array}{ll}\text { CA10 } & \begin{array}{l}\text { crank angle ATDC of } 10 \text { per cent mass- } \\ \text { burned fraction } \\ \text { crank angle ATDC of } 50 \text { per cent mass- } \\ \text { burned fraction } \\ \text { crank angle ATDC of } 90 \text { per cent mass- } \\ \text { burned fraction } \\ \text { CA90 }\end{array} \\ \text { Fmbf } & \begin{array}{l}\text { the final mass-burned fraction } \\ \text { CATrans }\end{array} \\ & \begin{array}{l}\text { tioned to CI } \\ \text { tiongle the combustion transi- }\end{array}\end{array}$

CATrans was computed as the CA of maximum second derivative of the HRR $\mathrm{d}^{2} \mathrm{HRR} / \mathrm{dCA}^{2}$; justified based on the arguments given in section 2. These parameters were tabulated and crosscorrelated with the image and spark-discharge parameters discussed in the following sections. CA50 is used to quantify the combustion phasing of the main portion (CI) of the heat release. It is also used conditionally to sample cycles within the heat-release analysis to average data from cycles with like phasing. Conditionally sampled ensemble averages of the cycle-resolved measures HRR(CA), mbf(CA), and flame area, $\mathrm{A}_{\mathrm{flm}}(\mathrm{CA})$ were computed for the SACI operation also (e.g. Fig. 1).

The heat release code was modified to identify cycles that had image and spark-discharge records and to register these cycles with the pressure records. Cycle identification was necessary because images and spark-discharge records were not available every engine cycle. Specifically, each engine test recorded 300 cycles of pressure data; however, the first image did not occur on the first recorded pressure cycle and images could be recorded only every third or fourth engine cycle, randomly. Furthermore, although the oscilloscope could record spark-discharge data on every cycle, it experienced random drop-out also. Thus, cycle identification was required and accomplished by recording the oscilloscope-time-base gate and the image-intensifier gate along with the in-cylinder pressure. The conditionalsampling algorithm was used to compile a table that related the pressure-data-cycle number with the image-record number, and spark-discharge-record number.

\subsection{Imaging}

A high-speed framing camera (LaVision Speed Star) with a lens-coupled intensifier (LaVision IRO) was used for recording both the spark-discharge plasma channel and the combustion chemiluminescence. The camera has a dynamic range of 12 bits with an overall gain of approximately 6 . The spatial resolution here was $1.9 \mathrm{pixel} / \mathrm{mm}$. For these tests the frames were recorded at up to 1 per CA $(167 \mu \mathrm{s})$ per image with $40 \mu \mathrm{s}$ gated-intensifier exposure times. The camera records one 16 -frame image per cycle at approximately $3 / \mathrm{s}$; this was imposed by the transfer time of the images to the random-access memory (RAM) of the host computer. The limitation of 80 images per test, noted in the previous section, was imposed by the 2 Gbyte RAM on the host computer.

A Halle $50 \mathrm{~mm}$ f/2.5 UV lens with a $375 \pm 25 \mathrm{~nm}$ optical bandpass filter was used to image either the spark-discharge or the combustion chemiluminescence. This filter was used for imaging the sparkdischarge as it is centred about the cyanide $(\mathrm{CN})$ emission wavelength; this was used for sparkdischarge AF measurements as described in the next section. The same filter was used for imaging the CI combustion chemiluminescence, as it removed $\mathrm{C}_{2}$ chemiluminescence from rich burning as well as incandescence. The filter resulted in imaging of both the flame-kernel and HCCI combustion chemiluminescence; this filter is presumed to capture chemiluminescence from both $\mathrm{HCO}^{*}$ and the $\mathrm{CO}+\mathrm{O} \rightarrow$ $\mathrm{CO} 2+\mathrm{h} v$ continuum during combustion [16]

The spark discharge and flame propagation could not be imaged during the same tests for two reasons. Firstly, all 16 frames were required to resolve adequately either the spark-discharge (1 image/CA for $15^{\circ}$ ) or the flame propagation (1 image/2.5 CA for $35^{\circ}$ ) but were insufficient to do both. Secondly, the early kernel imaging required 100 per cent gain to assure that the earliest kernels were detected. The high intensity of the spark discharge would have damaged the intensifier. For both reasons, the spark discharge and early kernel development had to be recorded during separate tests.

Because the spark plug gap was in the bowl at TDC, it was not possible to image perpendicular to the window in the head. Instead, the camera was angled down $14 \pm 1^{\circ}$ as shown in Fig. 8. This provided a view of the spark-plug electrodes albeit distorted. It caused a further complication; light emitted or scattered from the top of the combustion chamber and above the direct field of view was reflected into the imaged field of view via the bottom 


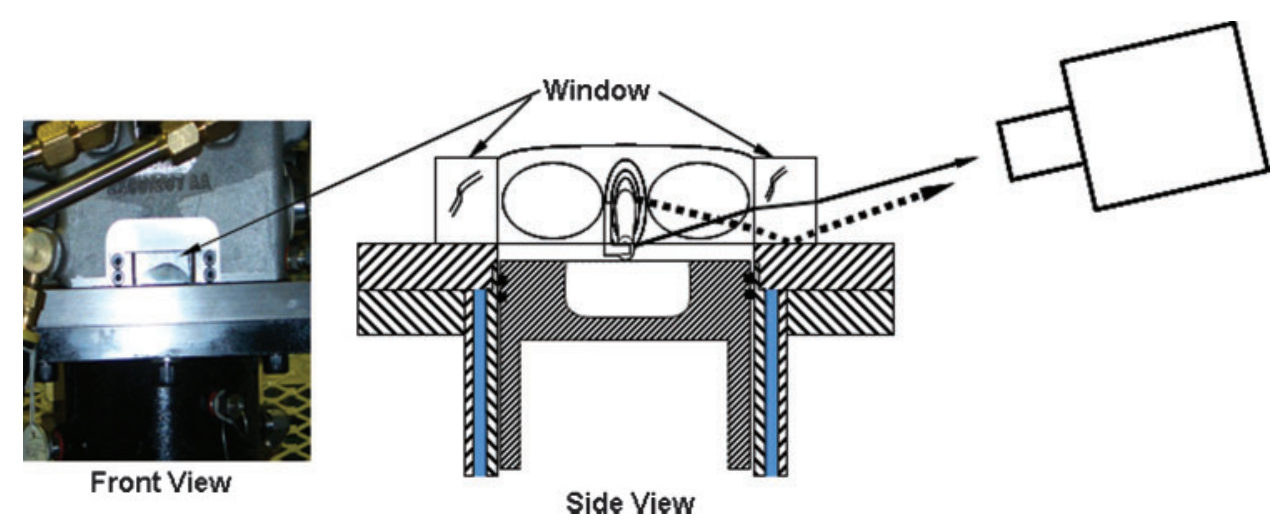

Fig. 8 Camera field of view and reflections from the bottom of the window

surface of the window. This is illustrated by the dotted line in Fig. 8. An image of the bowl, spark plug, and combustion chamber are shown in Fig. 7(a) while illuminated with a white light. The double images shown in Fig. 7(a) are a result of reflections illustrated in Fig. 8. The ramifications of the reflected images on the image processing will be discussed.

\subsection{Spark-discharge measurements and analysis}

The spark discharge event was recorded both by measuring the electrical discharge and by imaging the plasma channel. Several metrics were computed from the spark discharge secondary-voltage and secondary-current measurements and correlated with CA50. Plasma-channel excursion, measured from the images, was correlated with CA50.

\subsubsection{Electrical measurements}

The secondary voltage and current were recorded during each engine cycle with a digital oscilloscope (time-based) sampling once per $\mu$ s. A Tektronix 6015 high-voltage probe and a Pearson 110 current monitor (with a $100 \times 1 \mathrm{Mhz}$ amplifier) were used for this purpose. An example of the record from a discharge is shown in Fig. 9(a). This shows an unresolved breakdown and arc discharge followed by the long glow discharge. The beginning of the discharge, SOSpk, is measured as the time of the current rise, and is set equal to the spark angle on the CA encoder based engine-controller spark angle. The end of discharge, EOSpk, was defined as the time at which the current returned to zero and generally was coincident with the disappearance of the plasma channel images. The voltage signal after
$I_{\text {spk }}=0$ is the dissipation of the residual charge in the coil.

The following spark-discharge parameters were computed for each cycle from the spark-discharge current and voltage records.

$\begin{array}{ll}\mathrm{E}_{\text {gap }} & \text { total energy delivered to the gap } \\ \mathrm{P}_{\text {gap }} & \text { total power } \\ \tau_{\text {spk }} & \text { spark discharge duration } \\ \mathrm{I}_{\mathrm{CN}} / \mathrm{E}_{\mathrm{i}} & \text { spark AF } \\ \mathrm{dV} / \mathrm{d} \tau_{\text {spk }} & \text { voltage-decay rate }\end{array}$

$\mathrm{E}_{\text {gap }}$ and $\mathrm{P}_{\text {gap }}$ were computed by integrating the product of the voltage and current between the beginning (breakdown) and end of the discharge $(I=0)$ minus the energy lost to the plug resistance. The duration is the time from SOSpk to EOSpk. $\mathrm{I}_{\mathrm{CN}} /$ $\mathrm{E}_{\mathrm{i}}$ was used as a measure of the AF in the spark-plug gap at SOSpk, AF as described by Fansler et al. [17], where $\mathrm{I}_{\mathrm{CN}}$ is the intensity of the $\mathrm{CN}$ emissions recorded by the intensified camera averaged over the first image after the spark breakdown and $\mathrm{E}_{i}$ is the discharge energy delivered to the gap during the camera exposure. $\mathrm{dV} / \mathrm{d} \tau_{\text {dur }}$ was used in an attempt to characterize the velocity at the spark plug as described by Maly $[\mathbf{1 8}, \mathbf{1 9}]$. This was found to be inadequate. Instead, imaging was used to record the maximum plasma-channel excursion during each cycle as described in the next section.

\subsubsection{Imaging of the plasma channel}

To indicate the effect of the flow on the discharge, the spark-discharge plasma channel was imaged and the maximum excursion of each cycle computed. A single parameter was used to correlate the cycleto-cycle spark-discharge plasma-channel excursions with cycle-to-cycle variations in combustion 


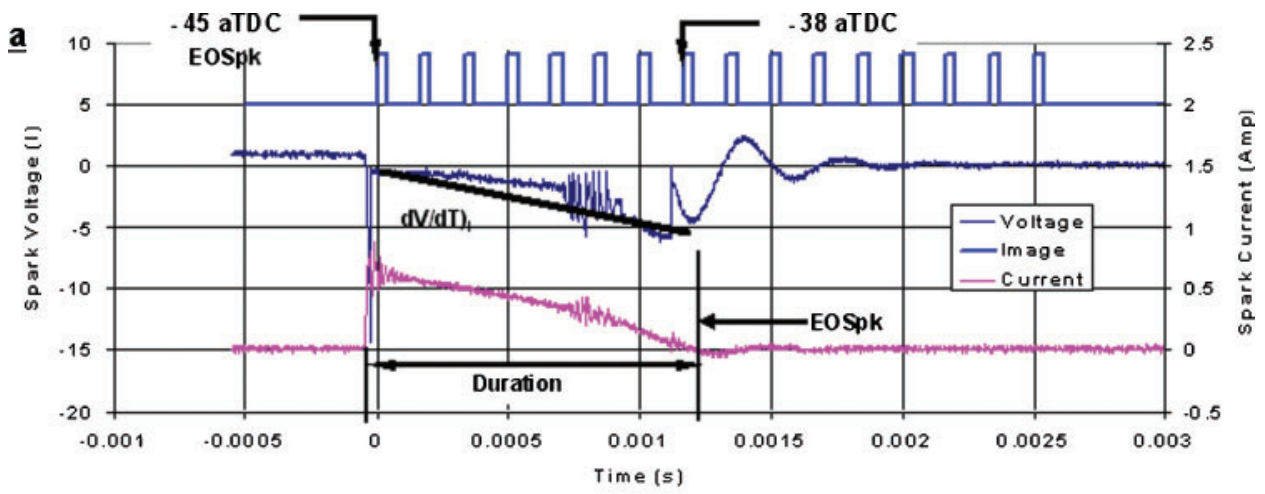

b
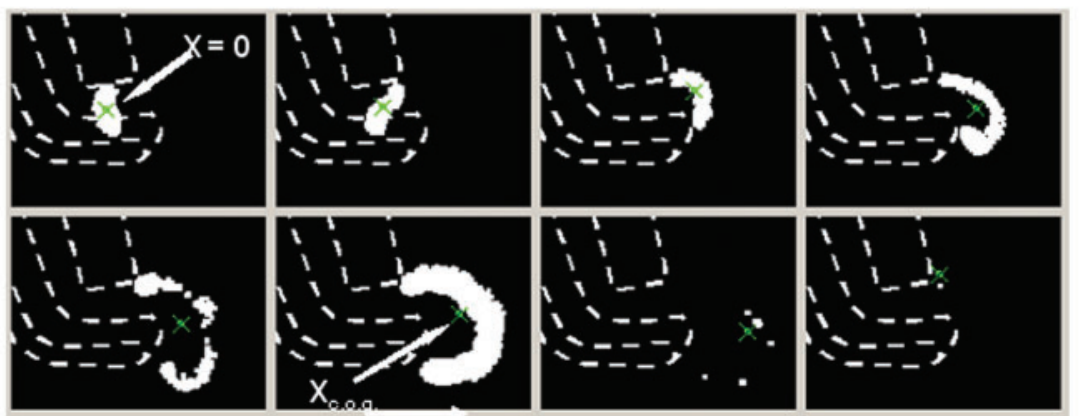

Fig. 9 (a) Current and voltage record and (b) binarized image of a plasma discharge form the same cycle. The ' $x$ ' marks the c.o.g. position computed from each image

phasing, namely,

$$
\begin{aligned}
\mathrm{MaxX}_{\mathrm{cog},}= & \text { maximum distance (during a cycle) } \\
& \text { from the centre of the electrode gap } \\
& \text { to the plasma centre of gravity. }
\end{aligned}
$$

To measure this, one 16-frame image per cycle was recorded of the spark-discharge channel taken at a framing rate of one per CA $(0.167 \mathrm{~ms})$ for 15 CAs $(2.5 \mathrm{~ms})$. The $2.5 \mathrm{~ms}$ range was adequate for determining the maximum excursion, in spite of the fact that there was a small percentage of cycles that lasted up to $3 \mathrm{~ms} ; 2.5 \mathrm{~ms}$ was adequate because longer duration discharges occur in cycles with little flow and therefore little or no plasma-channel excursion. The voltage and current traces from a cycle are shown in Fig. 9(a) along with the intensifier-gate signal. Processed images of the sparkdischarge plasma-channel in Fig. 9(a) are presented in Fig. 9(b). The outline of the spark-plug electrodes is superimposed for the purpose of illustration. The original images of plasma intensity were binarized at an intensity value of 0.03 times the maximum intensity within each image; thus, the threshold changes from frame to frame. This frame-to-frame threshold variation compensates for the large change in dynamic range during the discharge of each cycle and from cycle to cycle. Note that the last two images disappeared because the plasma chemiluminescence intensity falls below the threshold.

To quantify the excursion of the spark channel from the gap, the centre of gravity (average centre of area), $X_{\operatorname{cog}}=\left(x^{2} \operatorname{cog}+y^{2} \operatorname{cog}\right)^{1 / 2}$ was computed for each frame and tabulated for each imaged cycle. The $X_{\operatorname{cog}}$ for each frame is shown by the green ' $x$ ' in Fig. 9(b). The maximum excursion of the channel, $\mathrm{MaxX}_{\operatorname{cog}}$ during each cycle was then tabulated and correlated with other metrics in the spark and combustion processes. It is assumed that the impedance variations due to temperature and composition variations are small, and thus the cyclic variation of the spark channel excursion is dominated by the momentum of the velocity field.

\subsection{Chemiluminescence-image analysis}

The combustion chemiluminescence was imaged from the CA immediately after EOSpk and then taken every 2.5 CA thereafter. Thus, each 16 -frame image started at a different CA from engine cycle to engine cycle depending on the duration of the particular discharge. This is illustrated for two different cycles in Figs 10(a) and (b), which shows the first three intensifier-gate timings for a short and 

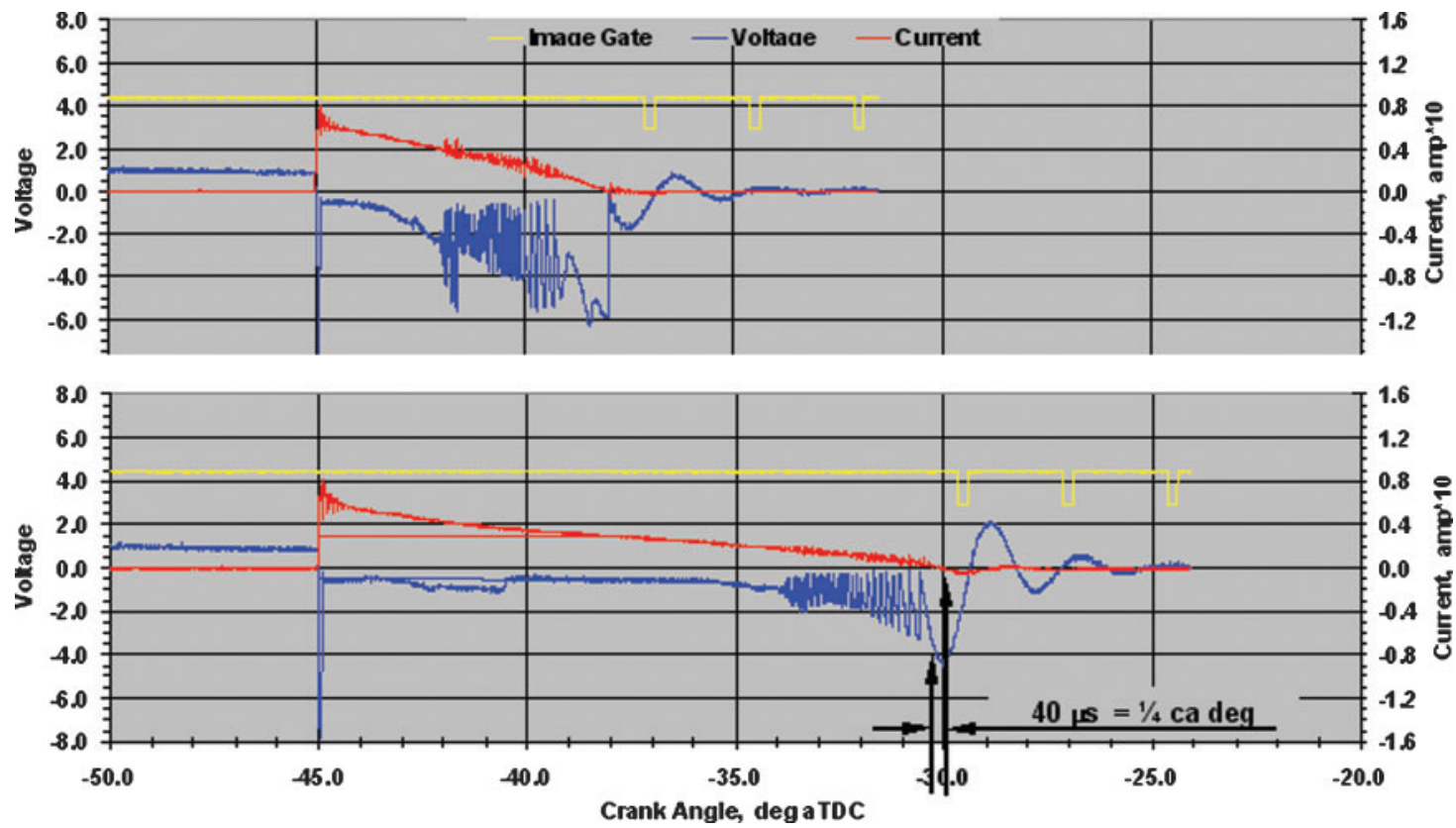

Fig. 10 Spark voltage and current records from two cycles illustrating the variable start-of-image acquisition

long spark discharge respectively. The first image frame was triggered $40 \mu \mathrm{s}\left(1 / 4^{\circ} \mathrm{CA}\right)$ after the sparkdischarge current fell to zero to assure the discharge plasma luminescence was over and thereby avoid intensifier damage. Since the spark-discharge duration range was from 1.15 to $2.5 \mathrm{~ms}$, the first frame on a given cycle was from -38 to -28 ATDC.

Sixteen-frame images from the same SACI cycle are shown in Fig. 11, where Fig. 11(a) is displayed with a linear scale and 11(b) is displayed with a nonlinear scale to enhance the low-intensity early kernel. Each image was processed to remove the random-pixel background noise, which was present due to the 100 per cent intensifier-gain setting. Also, a mask (Appendix 2) was applied as evident by the boundary in the last frame (+3.7 ATDC). The dynamic range is large because the early kernel has counts as low as 1 and as large as approximately $4 \mathrm{k}$ in the most intense cycles. The one count is considered significant during the EKG period, since the image-processing noise-rejection procedures (masking and shot-noise removal procedures described in Fig. Al of Appendix 2) were sufficiently severe that images with no early kernel (the weakest of the intensity) had no pixels above 0 count. Thus, the algorithm erred on the side of missing images with extremely weak chemiluminescence to assure that one count was valid. The goal of this severe count removal was to assure that little or no noise contributed to the flame area at the risk of losing very weak early kernels. As the transition to flame was a robust intensity change, this does not affect the computation of EOEkg, which is the only quantitative metric used here.

\subsubsection{Definition of flame parameters}

The images of the flame chemiluminescence were analysed to determine the following parameters.

$\begin{array}{ll}\mathrm{A}_{\mathrm{flm}} & \text { flame/kernel area in each frame } \\ \mathrm{I}_{\mathrm{flm}} & \text { average flame intensity in each frame } \\ \text { EOEkg } & \text { CA at the end of EKG }\end{array}$

The parameters computed for the images in Figs 11(a) and (b) are plotted in Fig. 11(c). To compute the flame area, the images were binarized ( 0 's and 1's, 1 = flame area, threshold to be discussed) and the pixels summed to give the flame area in that image. The average flame intensity was determined by multiplying the intensity of each frame by the binarized flame area in that frame and averaging over that area. EOEkg was determined from $\mathrm{A}_{\mathrm{flm}}(\mathrm{CA})$ as the crank angle where the second derivative of $A_{\mathrm{flm}}(\mathrm{CA})$ is maximum. This is justified by the observation that the early kernels and the subsequent flame had distinctly different areagrowth rates, as shown in the individual cycle of Fig. 11(c) and the conditionally-averaged curve in Fig. 1.

Two different thresholds were used for binarizing each image frame, a fixed '2-count' threshold was 
a
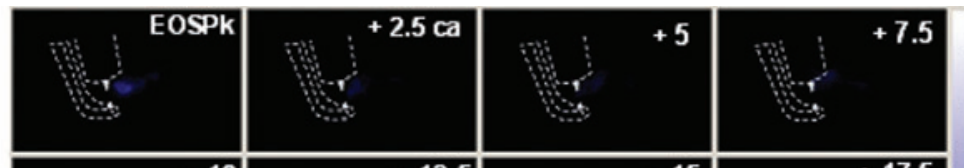

$1300=255$
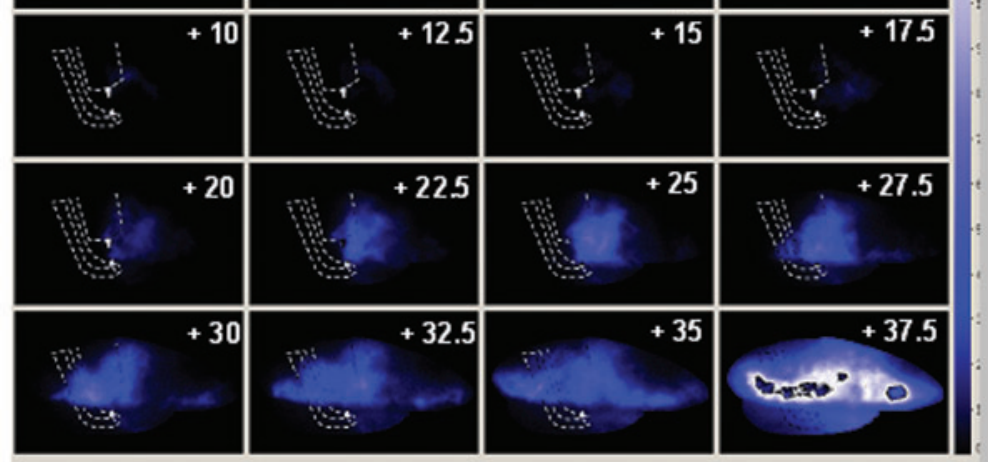

$975=172$
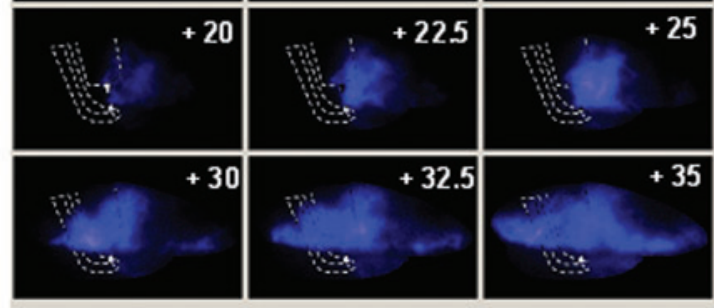

$325=64$

$650=128$

b
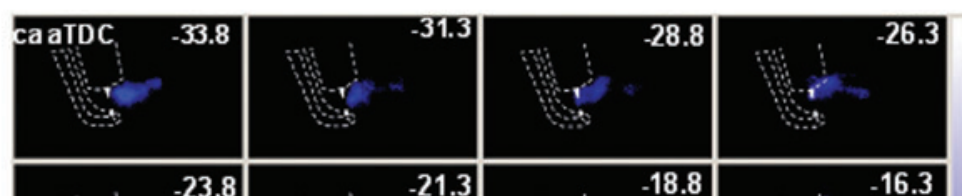

$1300=255$
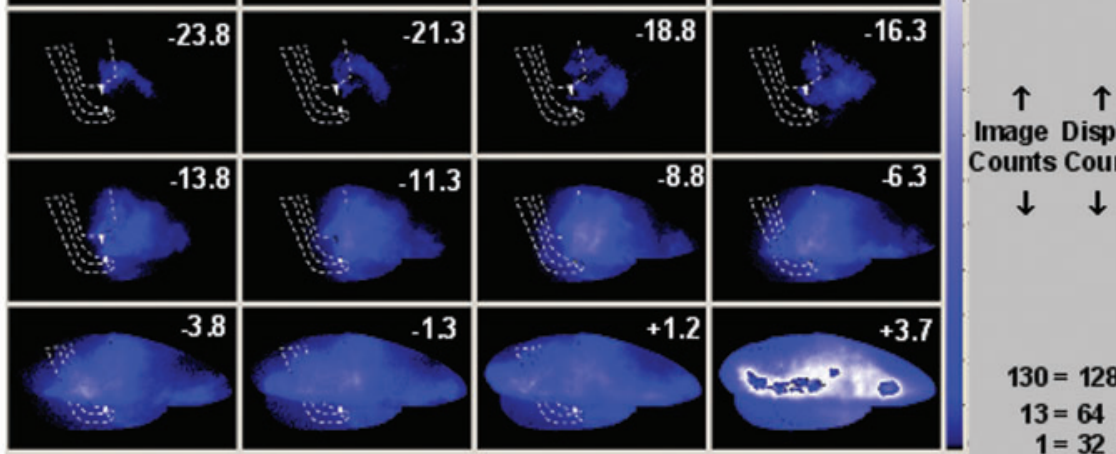

Image Display Counts Counts
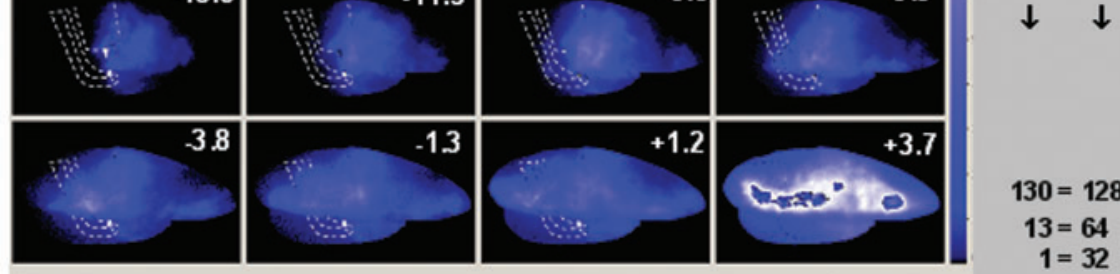

$130=128$

$13=64$

$1=32$

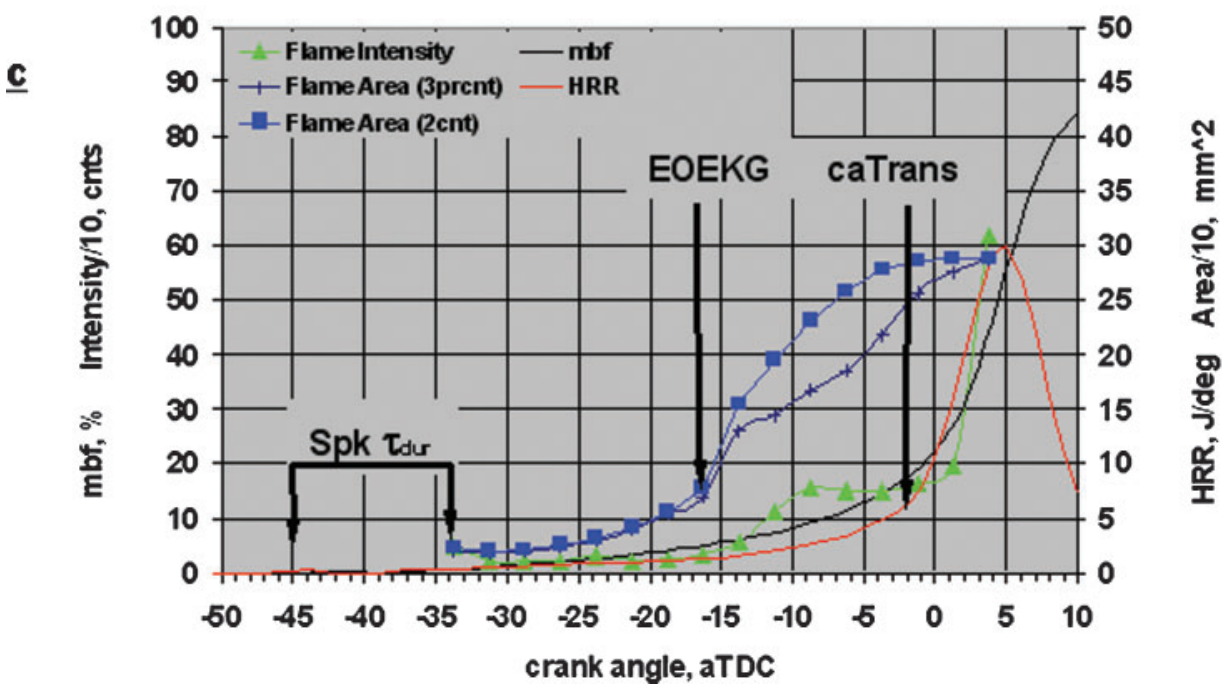

Fig. 11 Flame images from one cycle presented with (a) a linear intensity scale and (b) a nonlinear scale. The flame areas computed using the two-count and 3 per cent filters are shown in (c)

used to determine the EOEkg and a ' 3 per cent-ofmax' was used to define flame areas during the flame propagation period. The two-count threshold was found to be best for identifying the end of the EKG event since the EKG had weak luminosity and no background noise. Also, it provided a single maximum second derivative on the $\mathrm{A}_{\mathrm{flm}}(\mathrm{CA})$ curve (c.f. the curves in Fig. 11(c)); which is unambiguous for 
detection of the second derivative. However, the two-count threshold overestimated the area during the flame propagation period because of the much brighter background scattering; thus the two-count threshold would binarize most of the masked region. The high background light intensity could be from either or both of the (a) scattered chemiluminescence from the combustion chamber walls, or (b) early, low-intensity CI chemiluminescence.

The ' 3 per cent-of-max' binarization threshold set equal to one, all pixels whose intensities in a frame were greater than 3 per cent of the maximum intensity. This approach compensated for the very large dynamic range $\left(>10^{3}\right)$ of the chemiluminescence intensity during the flame propagation period, since it automatically tracks the flame-intensity increase. Furthermore, it rejects the increased background noise that occurred with increased intensity, and thereby produces a flame area that agreed with what could intuitively be seen by eye.* The 3 per cent-of-max threshold could be used to determine the EOEkg, but produced noisier results. A direct comparison of the two-count and 3 per cent-of-max thresholds revealed a 1:1 correlation with about 5 per cent outliers (Appendix 2). When cycles corresponding to these outliers were investigated, it was found that the 3 per cent-of-max threshold would produce two maximum second derivatives because the maximum-intensity increase from one frame to the next could sometimes produce a smaller area. This can be seen by comparing the two $A_{\text {flm }}(C A)$ curves in Fig. 11(c). In any case, the major use of the threshold was to define the end of the EKG and estimate the observable flame area; the use of one threshold over the other does not alter the conclusions in this study.

\section{RESULTS}

\subsection{Discrimination of flame and CI chemiluminescence}

\subsubsection{Flame discrimination in single cycles with homogenous mixtures}

Discriminating between a flame and CI is difficult because chemiluminescence images from both types of combustion are spatially inhomogeneous $[\mathbf{2 0}, \mathbf{1 2}]$. Also, imaging is a volume integration; thus, at any given time both processes may be occurring in different regions of the volume. CI and SACI combustion could not be separated with spectral

*The use of intensity to discriminate between flame and CI chemiluminescence is fully discussed in section 4.

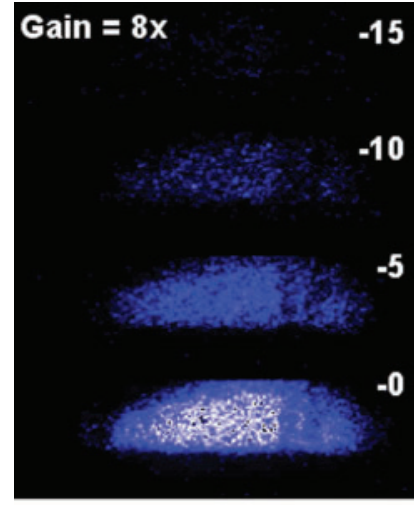

a. No spark ignition

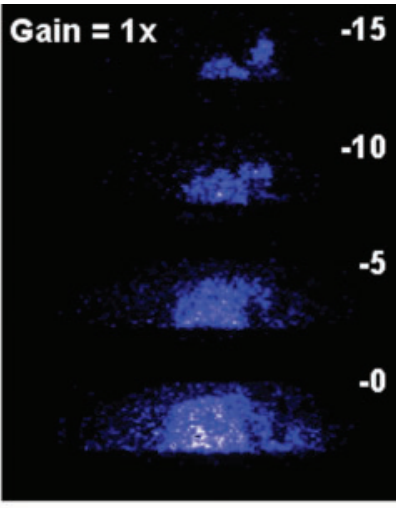

b. Spark ignition, 30 aTDC
Fig. 12 CI of homogeneous mixture (a) with and (b) without SI

filters because the spectral signatures overlap. In this study the intensity was used to define the sparkassisted combustion, which have here been presumptuously labelled as early (flame) kernels and flame propagation leading to CI. Of course, this is not rigorous but is based on empirical observations made in both homogeneous and fuel-stratified incylinder charges. The use of intensity to discriminate between 'flame' and CI combustion is justified as follows.

First, consider the case of spark ignition in a homogeneous mixture that creates a reaction kernel with greater intensity than the CI but does not contribute to the heat release. This is demonstrated in Fig. 12, which shows images from two different homogeneous cycles (single-early injection, $7.5 \mathrm{mg} /$ cycle) at different intensifier gains, one cycle with and one cycle without spark discharge. These images were taken in this engine using a multi-framing CCD having a direct-coupled intensifier (LaVision, Streak Star) with an optical bandpass filter at $375 \pm 25 \mathrm{~nm}$, which has higher sensitivity than the lens-coupled framing camera (LaVision, Speed Star). Figure 12(a) shows pure CI operation, which produces chemiluminescence that is spatially uniform. Figure 12(b) shows the same operation with the spark turned on; the spark created a localized high-intensity chemiluminescence region that grew in spatial extent, albeit slowly, and was eight times more intense than the HCCI chemiluminescence at the same CA. The latter image is interpreted as chemiluminescence from a reacting kernel initiated by the spark. The engine-combustion phasing based on LPP and heat release analysis was unaffected by the spark at this high-dilution and low fuelling rate. The point here is that even in a very homogeneous highly dilute environment, where the spark assist did not 
contribute to compression ignition (i.e. was not detectable with heat-release analysis and did not alter the combustion phasing), the reaction kernel could be discriminated from the CI combustion based on intensity. As noted in the introduction, it is not possible to proclaim that this is a true flame, but it is reasonable to assume the chemiluminescenceintensity increase is an indication of a reacting kernel.

\subsubsection{Flame discrimination in individual cycles with stratified mixtures}

Next, consider the applicability of flame discrimination based on intensity with fuel-stratified engine operation, where spark-assisted combustion does affect combustion phasing. Here, the intensity of the spark-ignited reaction kernels from three individual cycles during the fuel-stratified SACI engine operation characterized in Table 1 is compared. The purpose is to demonstrate, in detail, SACI combustion evolution during three individual cycles with early to late phasing. Figure 13 shows 16 -frame images from three different cycles corresponding to CA50 $=-2,+2$, and +8 ATDC. The 16 frames on the left of each image were binarized with a 3 per centof-maximum value as described previously; the frames to the right are the original images displayed with the non-linear scale of Fig. 11(b). The EOSpk, EOEkg, and CATrans are indicated based on the spark-discharge measurements, image analysis, and heat-release analysis respectively. The heat-

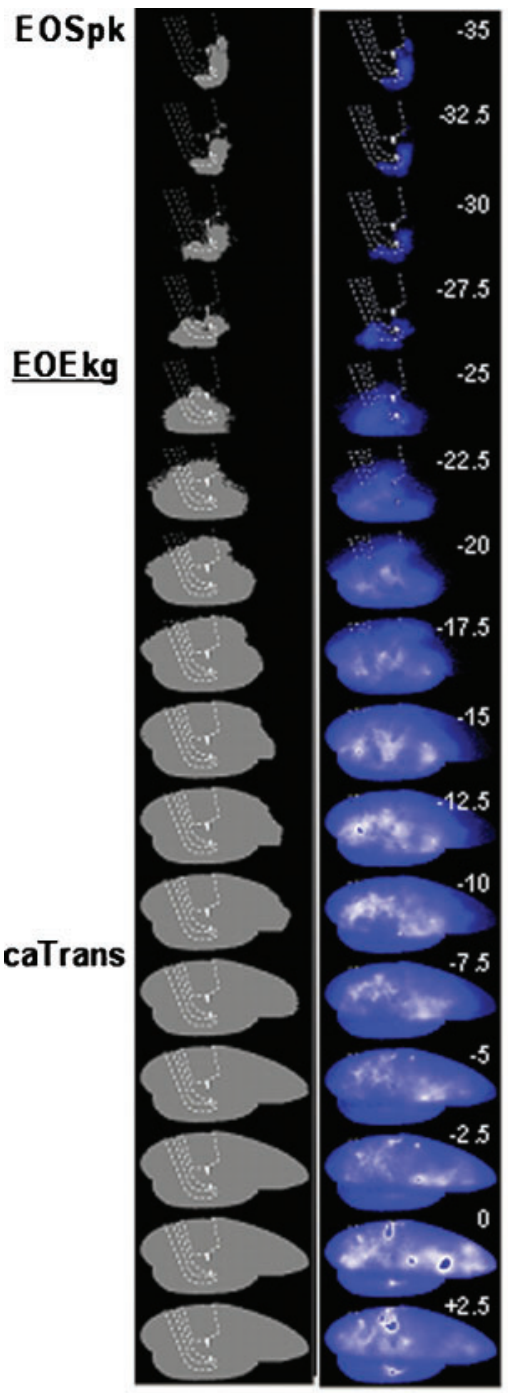

a) $\operatorname{ca50}=-2$ aTDC

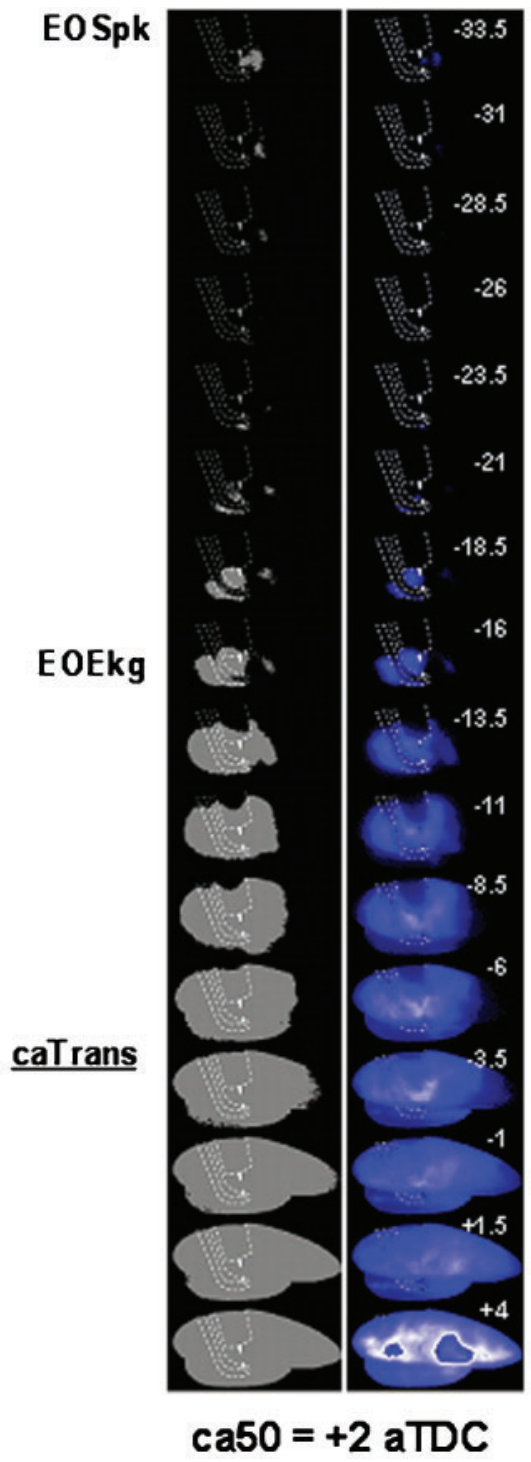

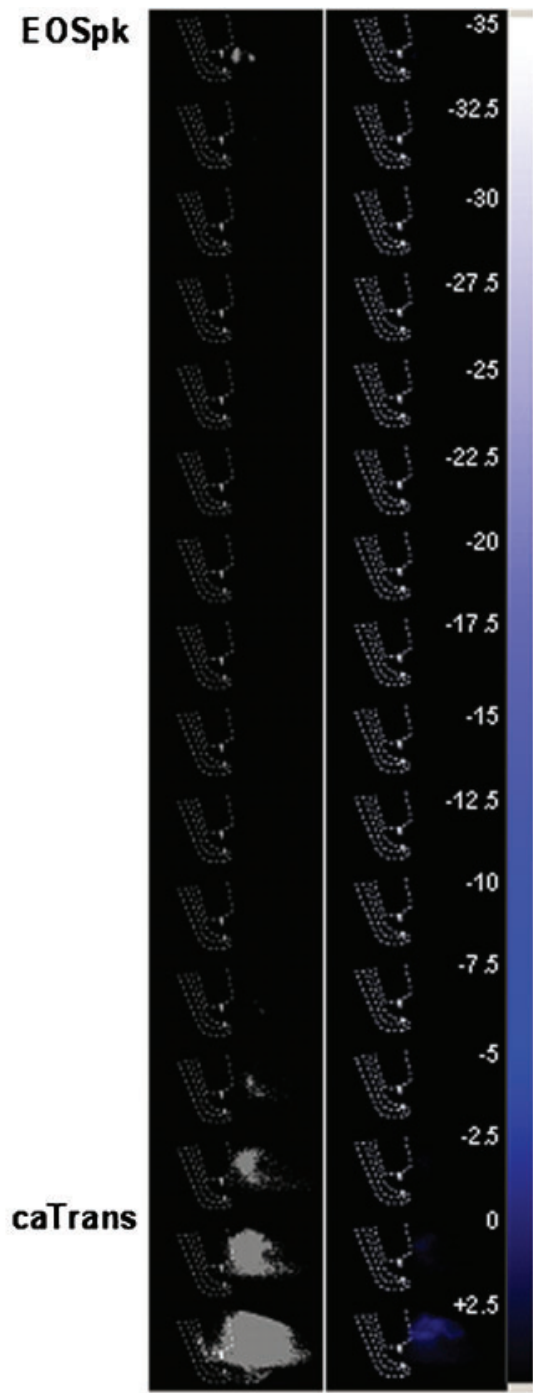

c) $\operatorname{ca} 50=+8$ a TDC

Fig. 13 Binarized images and intensity images of cycles with (a) early, (b) late, and (c) no EKG after spark 


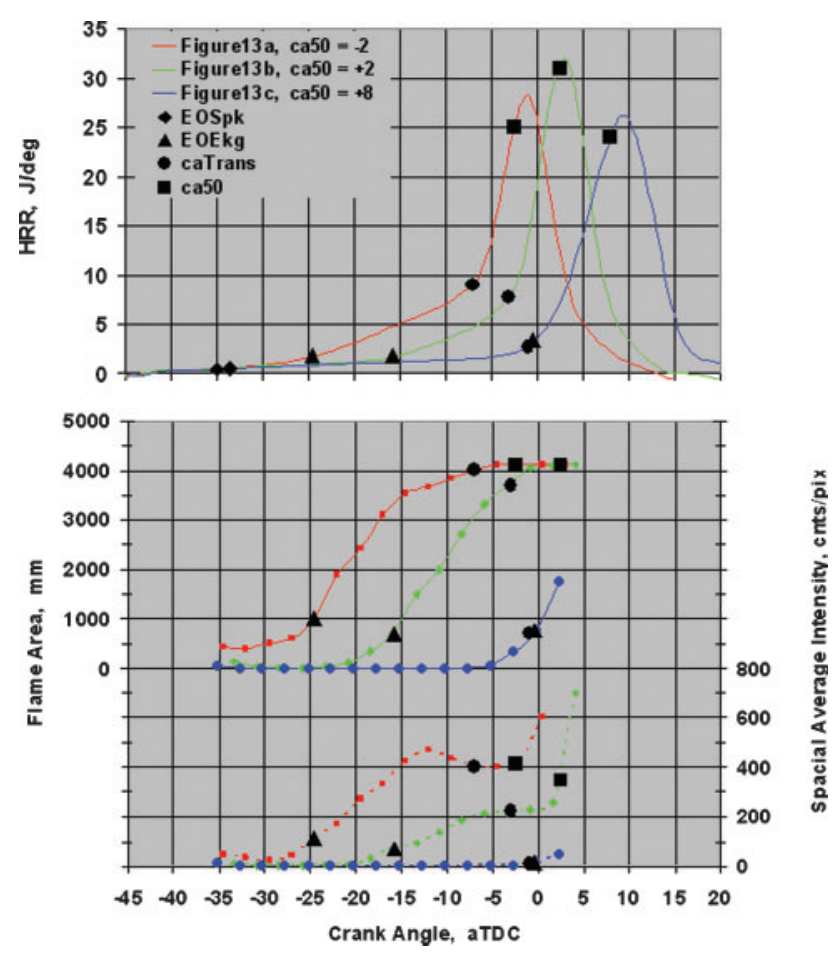

Fig. 14 HRR: (a) flame area and intensity; (b) for the three cycles shown in Fig. 13

release curves, flame area, and spatially-averaged flame intensity corresponding to these three cycles are presented in Fig. 14. In all three cycles a reaction kernel existed at the end of the spark discharge, EOSpk, as indicated by the binarized images where a kernel exists in the first frame of all three images. Considerable variation exists after this first image.

In Fig. 13(a), the cycle with the earliest CA50, the reaction kernel chemiluminescence was present immediately after EOSpk, remained visible as it grew in spatial extent until it filled the entire field of view. Comparison of Fig. 13(a) with Fig. 14 reveals the three periods of combustion following spark-discharge. During the EKG period (EOEkg-EOSpk) the area and intensity of the reaction kernel change little and no significant heat release occurs. During the flame period (CATrans-EOEkg) the reaction kernel area and intensity grow significantly along with significant heat release. During the CI period (CA > CATrans) the area cannot grow since the chemiluminescence fills the field of view. However, the HRR and intensity grow at a significantly faster rate.

Figure 13(b) shows a spark-assisted cycle that, although delayed, still advanced the combustion cycle earlier compared to a pure CI cycle. In this cycle, the kernel that existed at EOSpk almost disappeared until -18.5 ATDC. The disappearance occurs because either (a) the kernel was behind the plug,

(b) the kernel intensity became low and undetectable, and/or

(c) kernel moved into the bowl and returned.

The description of the three combustion periods given for the cycle of Fig. 13(a) apply identically to Fig. 13(b) except that the duration of the EKG period is longer for the latter.

Figure 13(c) shows a very late burning cycle where the initial kernel disappeared, and there was no indication of flame propagation in either the image or heat-release analysis, essentially a pure CI cycle. A chemiluminescence image appeared only after the HRR transitioned to high values consistent with CI combustion at CATrans $=-1$ ATDC. No chemiluminescence was detected prior to CATrans where there is an almost constant near-zero HRR. This low HRR prior to CATrans is always observed in late SACI cycles and is always observed in pure CI engine operation (early-injection). Although this could be due to inaccuracy of the heat-release/heat-transfer model, it is reasonable that a small amount of heat release does exist due to the hydrocarbons and CO in the 60 per cent rebreathed residuals. There could in fact be a constant HRR release but no chemiluminescence was recorded because it did not exist, the intensity was too weak to be detected by this camera, or the chemiluminescence was hidden from the field of view.

The images of the three example cycles in Fig. 13 demonstrate that the intensity-based discrimination of the flame is reasonable both in the homogeneous and the fuel-stratified spark-ignited mixtures, at least to the end of the EKG period. The images also demonstrate that there is a time between the end of the spark discharge and the beginning of the detectable heat release (beginning of the flame) when a reaction kernel exists, as evidenced by the chemiluminescence, that may grow quite slowly or disappear. The end of this EKG period is followed by a more rapidly growing reaction kernel (labelled here as a flame) that shows both higher HRR and increased chemiluminescence. This comparison between images and the analysis also demonstrates that

(a) EOEkg and the beginning of the heat-release agree;

(b) CATrans occurs at the same time that the chemiluminescence fills the field of view and has an intensity that begins to exceed that of the flame.

The importance of (a) is that EOEkg is a valid metric to describe the beginning of the flame, which will be used to determine the phase delay between 
the end of spark and beginning of flame propagation with measurable heat release. The EOEkg based on reaction-kernel area rather than the HRR is better because $d^{2} A_{\text {flm }}(C A) / d C A^{2}$ is a larger and more definitive change compared to either $\mathrm{d}^{2} \mathrm{P}(\mathrm{CA}) / \mathrm{dCA}^{2}$ or $\mathrm{d}^{2} \mathrm{HRR}(\mathrm{CA}) / \mathrm{dCA}^{2}$. Point (b) provides a visual corroboration that CATrans, which is determined by the heat release analysis, occurs at the beginning of the spatially distributed compression-ignition event. These conclusions have been demonstrated here for only three example cycles as it is impractical to publish many more. However, these conclusions have been observed to be true for many cycles from many different tests.

\subsection{Definition of EKG and flame combustion}

In this section the image-processing techniques demonstrated in Fig. 13 are used to show that the
$\mathrm{A}_{\mathrm{flm}}(\mathrm{CA})$ trends in Fig. 14 are applicable beyond these three cycles.

Figure 15 shows the flame area growth, $\mathrm{A}_{\mathrm{flm}}(\mathrm{CA})$, of many cycles conditionally sampled on CA50; each cycle-resolved plot begins at the EOSpk for its respective cycle. Figure 15 demonstrates that the features of $A_{f l m}(C A)$ observed in the three cycles in Fig. 14 can be generalized. Namely, there exists

(a) a slow or no area-growth-rate EKG period after EOSpk, followed by

(b) a relatively linear area-growth rate that achieves

(c) a maximum and constant area once the combustion image fills the field of view.

Figure 15 also demonstrates that (using the heavy line located at 10 ATDC as a guide) the duration of the EKG increases with CA50 delay. The success of the conditional sampling in classifying the early and late $A_{f l m}(C A)$ curves provides confidence that the
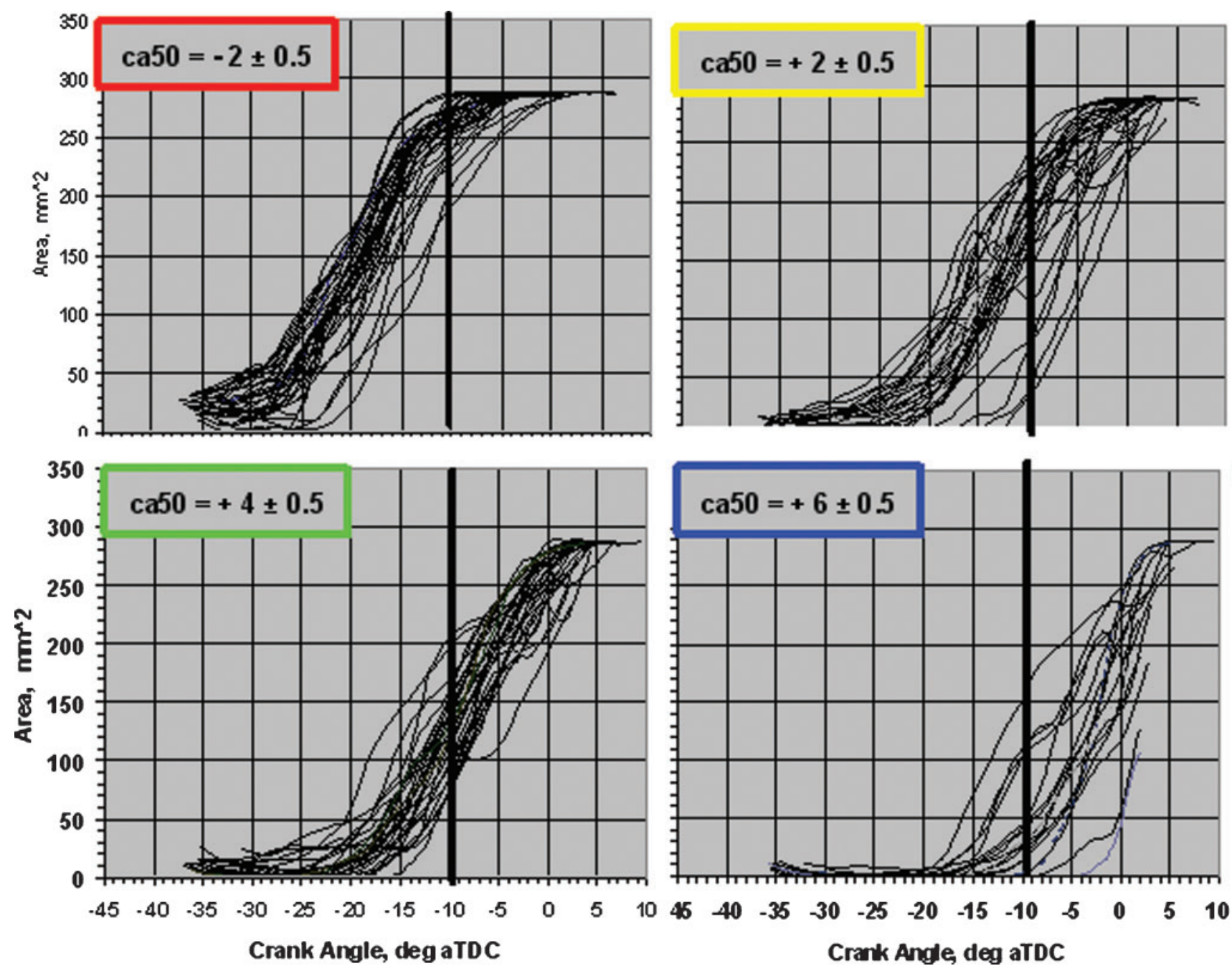

Fig. 15 Cyclic variability of the engine cycles conditionally sampled on CA50 


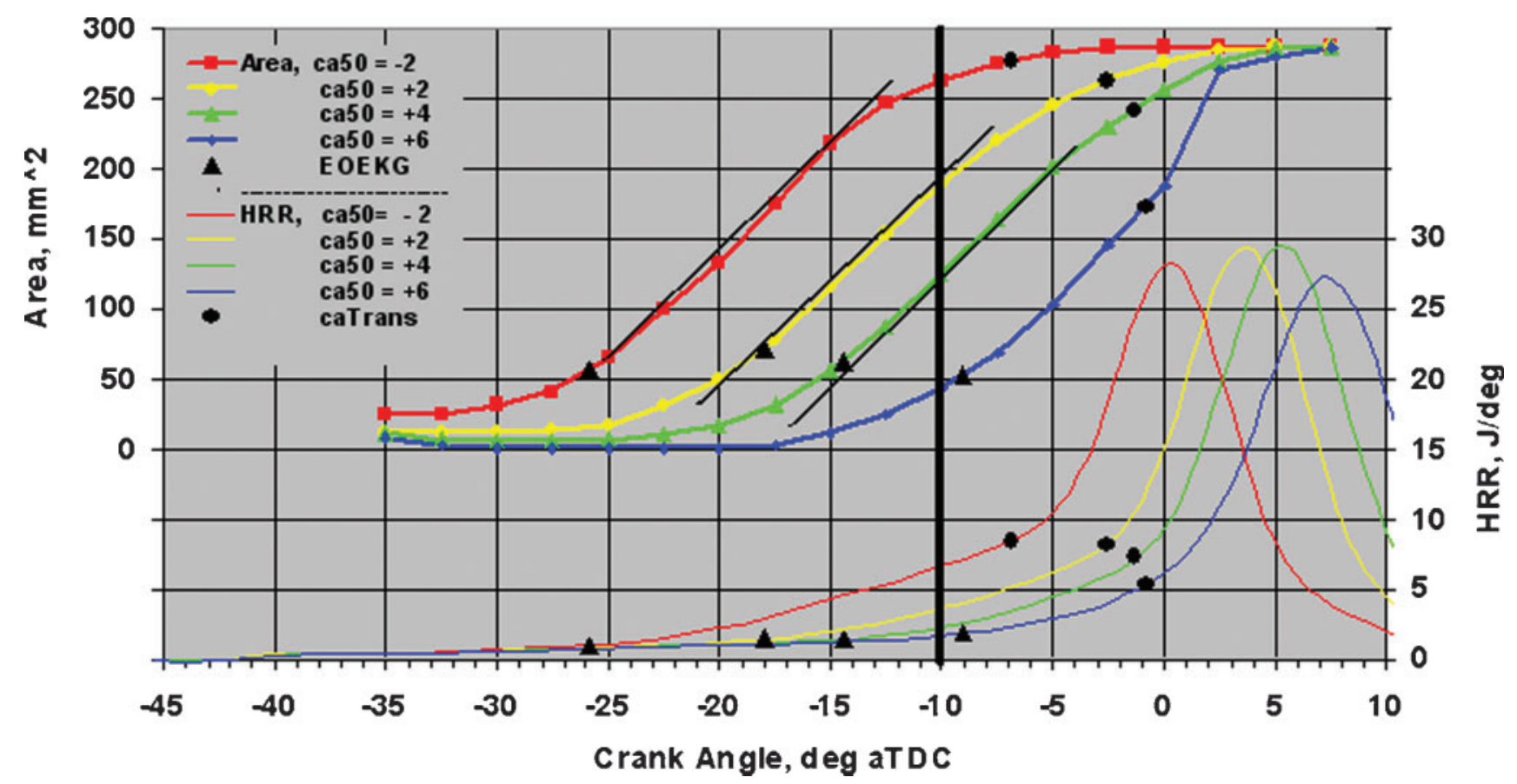

Fig. 16 Conditionally sampled ensemble-averages of the area growth and heat release in Fig. 15.

ensemble averages conditionally sampled on CA50 can be used to represent the EKG and flame periods of the individual cycles with like phasing (CA50).

Figure 16 plots conditionally sampled ensemble averages $\left.<\mathrm{A}_{\mathrm{flm}}(\mathrm{CA})\right\rangle_{\mathrm{CA5} 5}$ and $\left.<\mathrm{HRR}(\mathrm{CA})\right\rangle_{\mathrm{CA} 50}$, for the four different values of CA50 used in Fig. 15. The black lines (of equal slope) demonstrate that the area-growth rates have approximately the same linear growth rate after EOEkg, with the possible exception of the very late cycles of CA50 $=+6$, where CI rather than flame combustion is dominant.* The triangles, EOEkg, and filled circles, CATrans, on Fig. 16 are the conditionally sampled averages of the individual-cycle values; thus, their position does not precisely match the maximum-second-derivative point of the conditionally sampled averages. The following points can be made from Fig. 16 .

1. A benign combustion period (small area growth defined here as EKG) after the spark discharge exists with no detectable heat release.

2. EKG is followed by a period, defined here as a flame, of detectable but low HRR (based on

*Cautionary note: we cannot definitively conclude that this linear growth is a fundamental physical property both because these are two-dimensional projections of three-dimensional 'flames' and because the flame growth in the bowl is not in the field of view and thus the camera is not recording all of the flame area. pressure analysis) and linear area growth (based on the image analysis).

3. A short EKG period advances the CI combustion as measured by CA50.

The functional forms of the curves in Figs 15 and 16 are not important since, for the purposes of this study, the timing and duration of the EKG and flame periods only need be identified. Specifically, Figs 14 and 16 demonstrate that the EOEkg, computed from the $A_{\text {flm }}(C A)$ measurements, occurs at the first detectable rise in the HRR curve and is a consistent demarcation between the slow-growth EKG and fastgrowth flame periods both for the single cycles and the conditionally sampled ensemble-averages analysis. Further, CATrans, computed from HRR(CA) occurs when the $\mathrm{A}_{\mathrm{flm}}(\mathrm{CA})$ becomes constant as it fills the field of view. Thus, $A_{\text {flm }}(C A)$ and $\operatorname{HRR}(C A)$ provide mutually consistent metrics of the combustion process and EOEkg and CATrans, it is concluded, are valid metrics to quantify the boundaries between EKG-flame and the flame-CI periods.

\subsection{Cyclic variability of combustion phasing during the four combustion periods}

The contribution of each of the four periods to cyclic variability is assessed. To accomplish this, CA50 is correlated with the end of each period, EOPeriod, in Fig. 17 and the duration, $\tau$, of each period to 

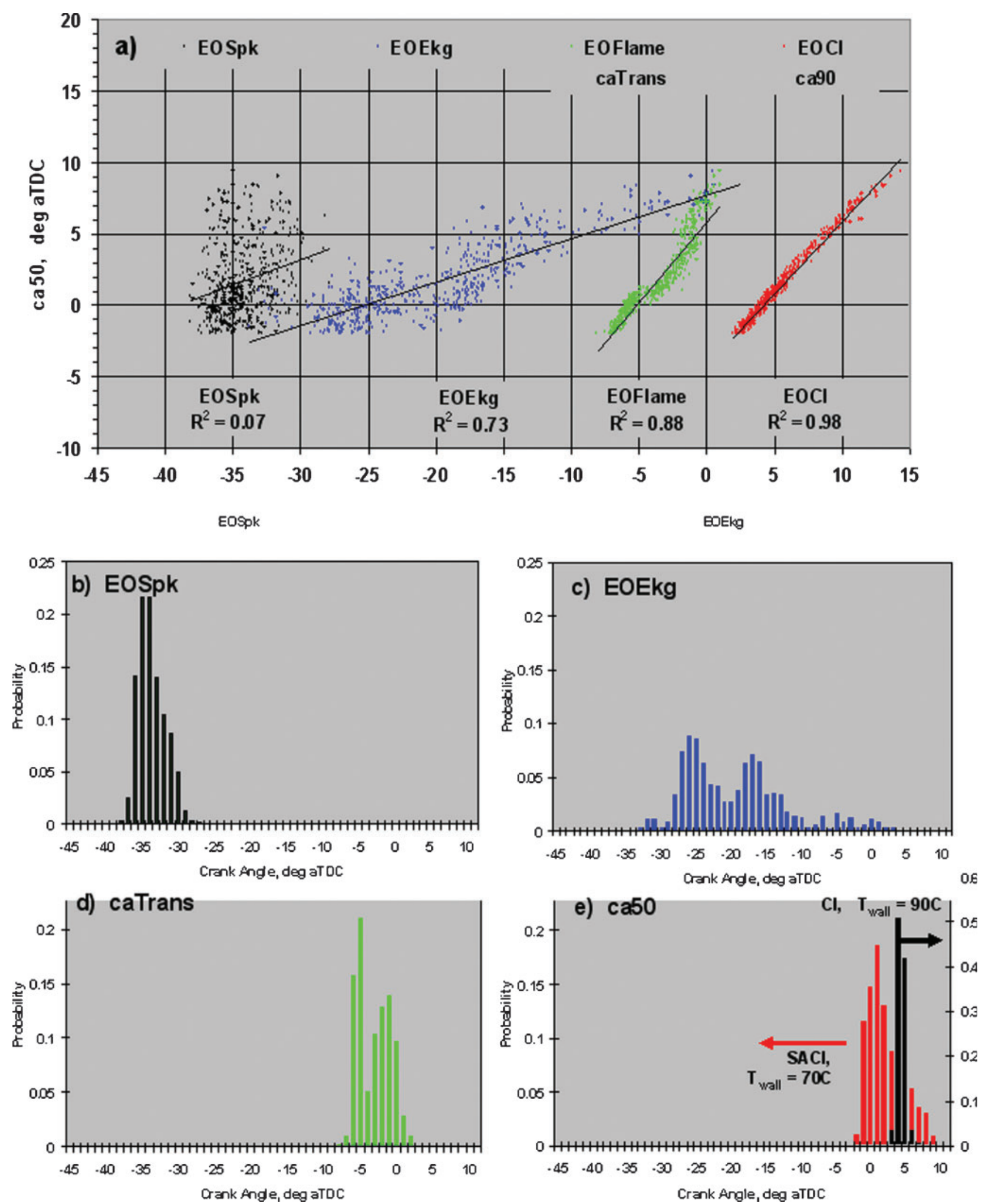

Fig. 17 Cyclic variability of the combustion periods (a) and the corresponding pdfs, (b)-(e) 

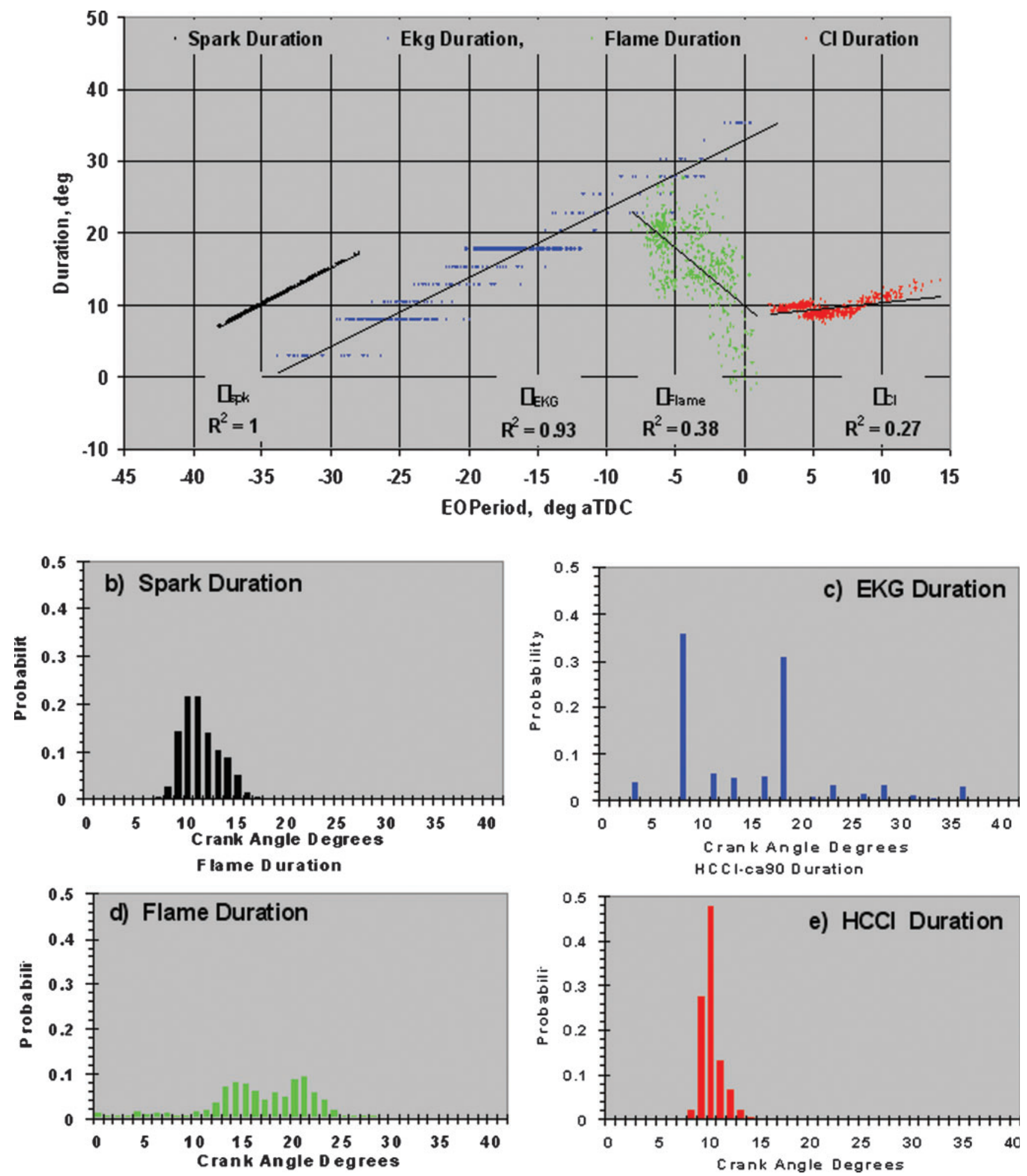

Fig. 18 Cyclic variability of the combustion period duration (a) and corresponding pdfs, (b)-(e)

EOPeriod in Fig. 18. Figures 17 and 18 will be used to identify the contribution of each period to the CA50 variability. The results in this section were presented backward in time $(\mathrm{CI} \rightarrow$ flame $\rightarrow \mathrm{EKG} \rightarrow$ ignition $)$ to demonstrate that as one moves earlier into the events, the phasing of the major portion of the heat release, CA50, becomes less correlated $\left(\mathrm{R}^{2}\right.$ decreases) with respect to the metrics measured here. The 
decrease in correlation is presumed to be due to either imprecision of the EOEkg and CATrans measurements (maximum second derivatives) or randomness in the physical processes. The source(s) of the randomness could include intercycle variability of the trapped charge (mass and composition) as well as intracycle velocity and composition distribution variations, none of which are measured here.

\subsubsection{CI period}

The CI period is characterized in Fig. 17(a) by plotting EOCI versus CA50 for 480 cycles, where EOCI was chosen as CA90. The very high correlation with CA50 demonstrates that once the combustion has reached 50 per cent mass burned, the second half of the combustion burns quite well at this operating set point. However, the roll-off from the linear fit at EOCI $>10$ suggests that cycles with a late CA50 will have a longer second-half of the burn. The roll-off is conjectured to be caused by the slowing of the $\mathrm{CO} \rightarrow \mathrm{CO}_{2}$ reactions in late cycles due to lower temperatures during expansion as suggested by Sjoberg [21].

Figure 17(e) compares the CA50 probability density function (pdf), * for SACI with that of similarly phased pure CI (i.e. no spark, early injection, and increased wall temperature to create a comparable average CA50, cf. Fig. 3(b)). Figure 17(e) reveals the large range of the SACI CA50 $\left(10^{\circ}\right)$, which is the motivation for this study. The skewness of the SACI pdf towards late cycles reveals those cycles that had poor spark assist and therefore relied on CI (c.f. Fig. 15, CA50 = +6). The duration variation of the CI period, $\tau_{\mathrm{CI}}=$ CA90-CATrans, is shown in Figs 18(a) and (e) to be small compared to the range of the CA50 variation (refer to ordinate range of Fig. 17(a)). Thus, once the SACI CI event has begun, its overall burning rate is about the same, regardless of phasing variations in CATrans, which accounts for the low $\mathrm{R}^{2}$ value for the duration in Fig. 18(a). This leads to the conclusion that the CA50 variations have been established prior to CATrans. This is not a universal conclusion, but must be qualified with the understanding that this operating condition resulted in all of the cycles being phased sufficiently early that high combustion efficiency (final mass burned) was achieved for all cycles.

\footnotetext{
*Two-and-a-half CA degree bins were used for all pdfs.
}

\subsubsection{Flame period phasing variability}

Figure 17(a) demonstrates that the EOFlame has a strong correlation $\left(\mathrm{R}^{2}=0.88\right)$ with CA50. This suggests that the major randomness in the CA50 variability must occur prior to the EOFlame, starting with the flame period. The unexpected shift in the very early and very late EOFlame cycles is assumed to be due to a complex relationship between the bimodal EOEkg and $\tau_{\text {Flm }}$ pdfs, which are discussed in this and the next sections.

Figure 16 demonstrated that the flame growth was approximately the same for flames started early or late. This suggests that the flame growth contributes little to the randomness but just passes on the phasing variations of the EKG period. This hypothesis is supported by two observations. First, that the two preferred EOEkg CAs in Fig. 17(a) ( -35 to -20 ATDC and -20 to -10 ATDC) are manifest as two preferred EOFlm CAs in Fig. 18(a) ( -8 to -5 ATDC and -5 to -1 ATDC), although the $\tau_{\mathrm{Flm}}$ of these two EOFlame crank angle preferences overlap. Secondly, the pdf of $\tau_{\text {FIm }}$ in Fig. 18(d) shows a bimodal distribution which was established during EKG as shown in Fig. 18(c). The two preferred $\tau_{\text {Flm }}$ pdf modes are wider than the two very narrow modes of the $\tau_{\mathrm{EKG}} \mathrm{pdf}$, indicating that randomness was introduced by the EOEkg. Since neither the phasing (CA50) nor the duration of the CI combustion show this bimodal distribution, the bimodality is apparently overcome by the main heat release during the CI period.

Figure 18(a) shows that the duration of the flame period, $\tau_{\text {Flm }}=$ CATrans - EOEkg, has a negative correlation, albeit weak $\left(\mathrm{R}^{2}=0.38\right)$; that is, the longest duration flames actually end earlier, thereby advancing the start of CI combustion (CATrans). Since the flame-area growth rates are approximately the same, regardless of when the flame begins (Figs 15 and 16), flames that start early create a longer duration flame tending to advance CI phasing (CA50). This point is better made in Fig. 19(a), which shows a stronger correlation between the EOEkg (start of the robust flame) and CATrans. Recalling that (a) the flame duration is the time between the start of a robust flame (EOEkg) and the onset of CI (CATrans), and (b) the early and late flames grow at the same rate, it follows that randomness in the start of the flame (EOEkg) is responsible for the flame duration variation.

\subsubsection{EKG period phasing variability}

Now consider the EKG period. Figure 17(a) demonstrates that the EOEkg has the largest range of values 

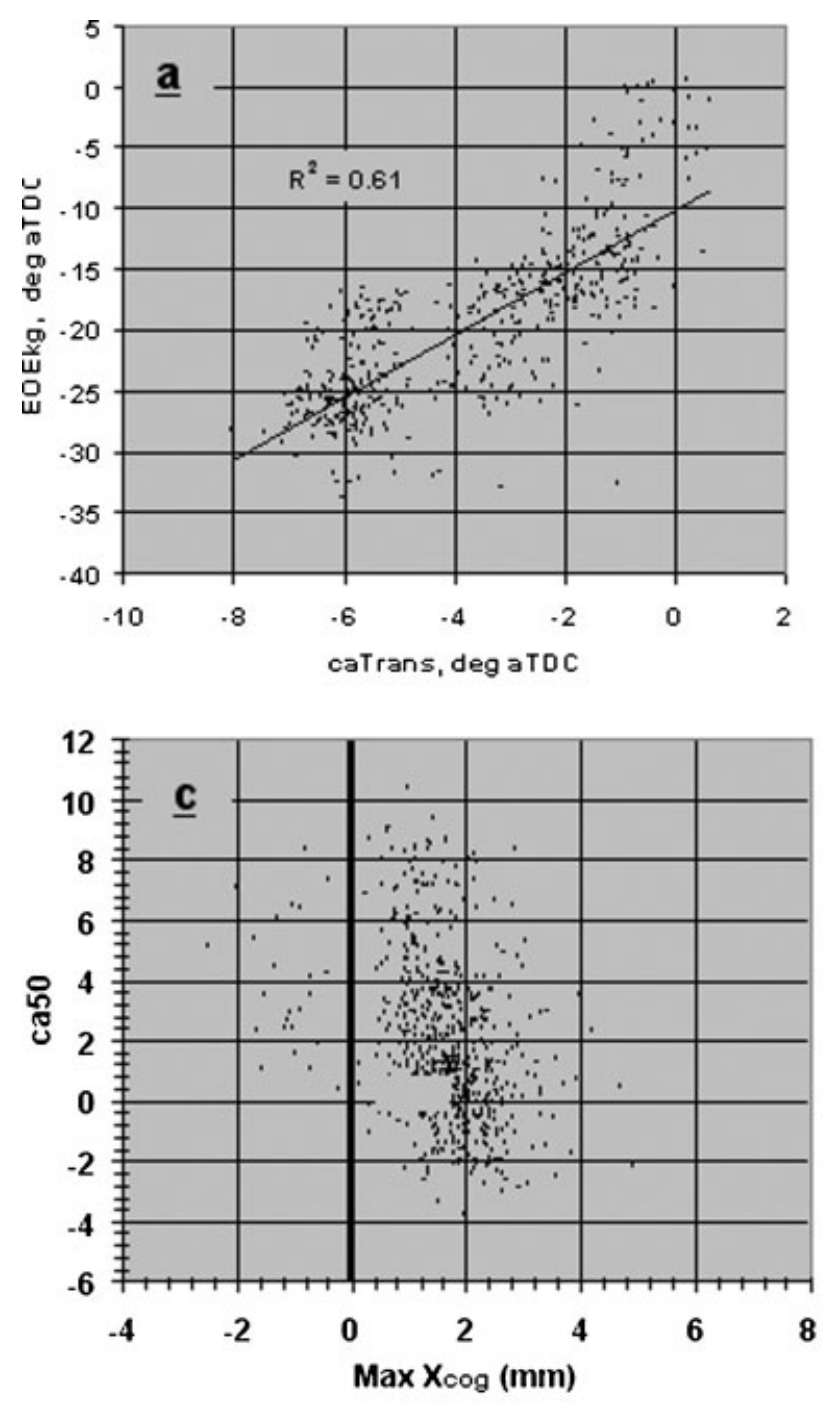
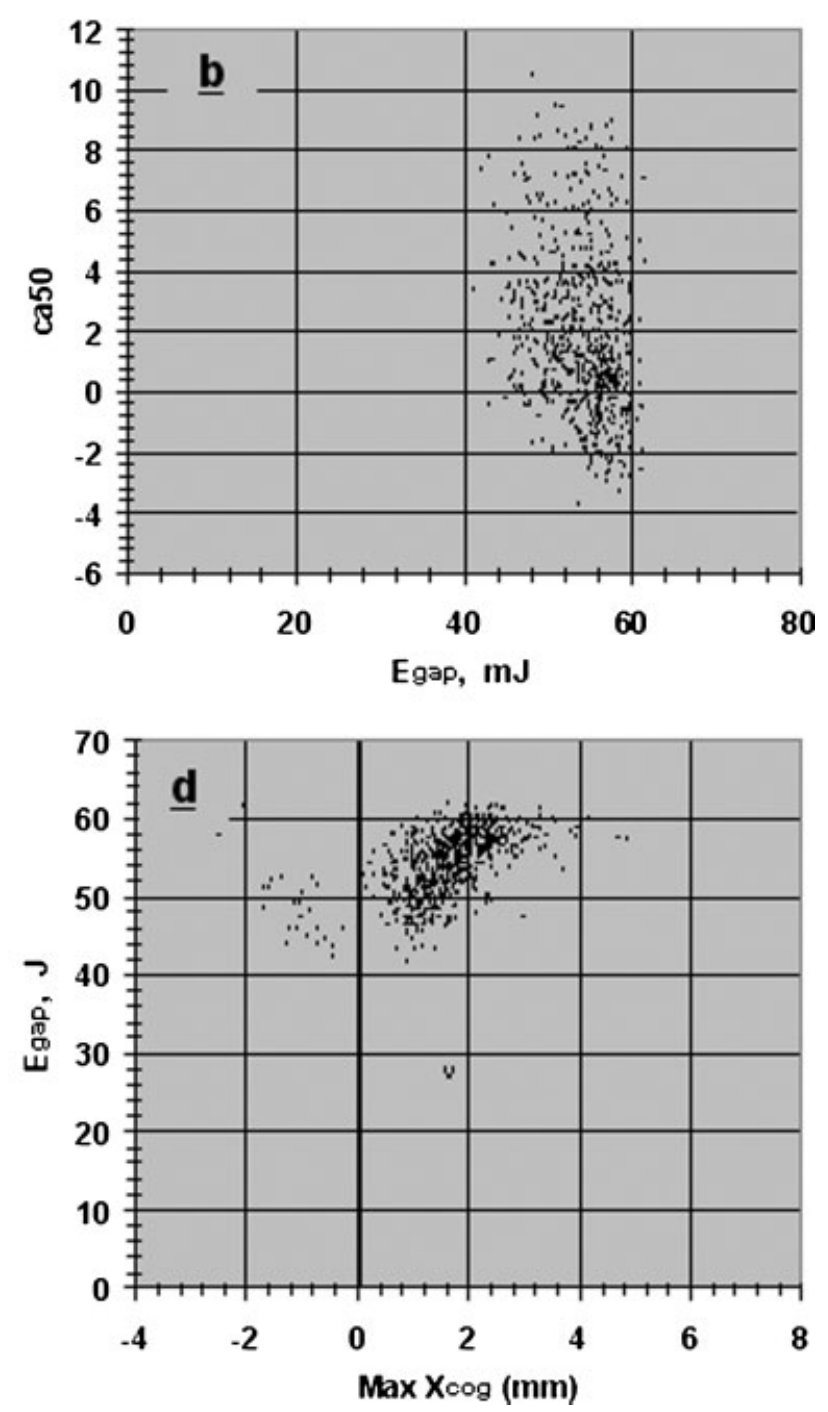

Fig. 19 Cyclic variability correlations of the beginning and end of the flame period (a) and the spark-discharge parameters, (b)-(d)

of the four periods and there is a strong positive correlation $\left(\mathrm{R}^{2}=0.73\right)$ between CA50 and EOEkg; early initiation of the flame period (EOEkg) results in advanced CI combustion. Also, bimodality is visible in the scatter plot of Fig. 17(a) as well as the EOEkg pdf in Fig. 17(c), which show that there are two preferred EOEkg CAs (one between -35 and -20 ATDC, the second between -20 and -10 ATDC). The origin of all of the bimodality observed in Fig. 17(c) is more obvious in the plots of Figs 18(a) and 18(c); Fig. 18(a) confirms that the range of the EKG duration is the largest of the four periods and Fig. 18(c) demonstrates that the EKG has two distinctly preferred durations. The narrowness of the pdf modes in Fig. 18(c) is exacerbated by the low image-sampling rate allowed by this camera (16 frames per cycle, $2.5^{\circ}$ apart). However, the $10^{\circ}$ peak separation is resolved adequately by the $2.5^{\circ}$ image- acquisition resolution. Further, the bimodality exists in the CATrans pdf, which is determined independently from pressure-based heat release analysis; thus the bimodality cannot be in question. The very narrow bimodal EKG duration, $\tau_{\mathrm{EKG}}$, in Fig. 18(c) demonstrates that the time to transition from the end of the spark plasma, EOSpk, to a robust flame, EOEkg, preferred one of two distinct states. However, the large overall range of the $\tau_{\mathrm{EKG}} \mathrm{pdf}$ $\left(36-3=33^{\circ}\right.$, refer to Fig. 18(c)) demonstrates more randomness in many of the other cycles. Since the range of $\tau_{\mathrm{EKG}}$ is much larger than the range of $\tau_{\text {Spk }}\left(10^{\circ}\right)$, there must be considerable randomness occurring during the EKG process itself.

The bimodality is interesting but its importance is unclear at this time, since it seems to be randomized during the flame and CI combustion prior to CA50; the cause of the bimodality is unknown at this time 
and left for future study. Notwithstanding, the large range in the EKG period has a major impact on the variability and the CI combustion phasing as the EOEkg is highly correlated with CA50.

\subsubsection{Spark-discharge period}

Firstly, consider the spark period in Fig. 17(a) $\left(\mathrm{EOSpk}=\tau_{\mathrm{spk}}\right.$ since all spark discharges start at -45 ATDC, cf. Fig. 18(a)). Here the EOSpk is seen to correlate poorly with CA50, as the range of CA50s is about the same at each EOSpk. There are many points about EOSpk, CA50 $=-35$, however, the pdf in Fig. 17(b) shows that EOSpk has a nearly normal distribution with but a slight skewness toward longer durations. The conclusion is that either the spark duration does not have an effect on the phasing of the CI combustion period or at least that any effect is randomized after the EOSpk.

Of the five spark discharge parameters, $\mathrm{P}_{\text {gap }}, \mathrm{I}_{\mathrm{CN}} /$ $E_{i}$, and $d V / d \tau_{\text {dur }}$ demonstrated no correlation with CA50 (e.g. $\tau_{\text {spk }}$ in Fig. 17(a)). $\mathrm{E}_{\text {gap }}$ and $\mathrm{MaxX}_{\text {cog }}$ exhibited a weak correlation with CA50. In particular, Fig. 19(c) demonstrates that a large excursion in the positive direction (toward the spray) is necessary, but not sufficient, to produce an early CA50. An advance in combustion phasing is expected with larger plasma-channel excursions based on work in homogeneous fuel-air mixtures [10]. This very weak correlation suggests that events after EOSpk randomly delay CA50. Figure 19(b) shows a similarly weak correlation between $\mathrm{E}_{\text {gap }}$ and CA50, but this is redundant with the $\mathrm{X}_{\operatorname{cog}}$ correlation as shown by the strong correlation between $\mathrm{E}_{\text {gap }}$ and $\mathrm{MaxX}_{\operatorname{cog}}$ in Fig. 19(d). The correlation between $\mathrm{E}_{\text {gap }}$ and $\mathrm{MaxX}_{\mathrm{cog}}$ is expected because the velocity is expected to be the dominant cause of the plasma-channel excursion* and higher flow velocities are known to result in higher $\mathrm{E}_{\text {gap }}[\mathbf{1 0}]$.

The weak correlation of $\mathrm{MaxX}_{\operatorname{cog}}$ with CA50 and the strong correlation of EOEkg with CA50 suggests that the plasma excursion may have an important influence on the EKG duration. However, it will be necessary to correlate the spark parameters with the EOEkg to reveal any interactions. This was not possible here because the camera could not record both the spark event and the EKG event owing to the

\footnotetext{
*It is, of course, possible that the discharge plasma might follow low-impedance paths created by gas or liquid fuel near the electrodes. However, it has yet to be demonstrated that fuel gradients or droplets can dominate the effect of the velocity.
}

low number of images per cycle. This correlation will be reported in a future study.

\section{CONCLUSION}

This study demonstrates that stratified-charge SACI is a mechanism to provide combustion-phasing control in gasoline HCCI engines, even at the light load condition ( $7 \mathrm{mg} / \mathrm{cycle}, 200 \mathrm{kPa}$ i.m.e.p.), where spray-guided direct fuel injection was required to achieve flame propagation. This study employed a combination of pressure-based heat-release analysis, spark-discharge voltage and current measurements, and cycle-resolved combustion imaging to define four periods of this combustion process, namely, (a) the spark discharge, (b) the EKG, (c) flame propagation, and (d) the CI periods. Metrics were defined to characterize each period and were used to identify the contribution of each of the four periods to the cycle-to-cycle phasing variability of the main CI heat release.

The following conclusions can be drawn for the engine operation studied here.

1. The entrainment of the spark-discharge plasma demonstrated a very weak correlation with the combustion phasing, CA50. It is hypothesized that the entrainment can affect CA50 through interactions with the EKG period. However, this could not be assessed here due to camera limitations.

2. The EKG period was the primary cause of CA50 cyclic variability. In particular, the EKG-period duration had the longest delay between spark and CA50, the largest range of cyclic variability, and a bimodal pdf (at this operating configuration). Shorter EKG periods resulted in longer flame durations, and earlier CA50 phasing.

3. The flame period exhibited flame-area-growth rates that were both linear and equal regardless of the CA at which the transition from EKG to flame (end of EKG, EOEkg) occurred. Thus, once strong flame propagation begins, variability during flame propagation does not contribute significantly to CA50 cyclic variability.

4. The CI combustion period was comparatively short, and the correlation between the transition to CI, CATrans, and CA50 was very high. Thus, the CI period did not contribute markedly to cyclic variability. The cyclic variability of CA50 is established prior to the start of CI combustion (CATrans). Since the flame growth rate and HRR are about the same and EOEkg is highly correlated 
with CA50, it is the variability during the EKG period that has the biggest effect on the CA50 cyclic variability.

\section{ACKNOWLEDGEMENTS}

The authors thank Jim Eng for his observations and consultations, as well as modifications to the HCCI heat-release analysis.

\section{REFERENCES}

1 Najt, P., Kuo, T.-W., Cleary, D., Eng, J., and Brown, B. Auto-ignition gasoline engine combustion chamber and method, US Patent US 6,971,365 B1, 2005.

2 Kuo, T.-W., Brown, B., Eng, J., and Najt, P. Method for mid load operation of auto-ignition combustion, US Patent US 6,994,072 B2, 2006.

3 Hyvonen, J., Haraldson, G., and Johansson, B. Operating conditions using spark assisted HCCI combustion mode transfer to SI in a multi-cylinder VCR-HCCI engine, SAE paper 2005-01-0109, 2005.

4 Weinrotter, M., Wintner, E., Iskra, K., Neger, T., Olofsson, J., Seyfried, H., Alden, M., Lackner, M., Wintner, F., Vressner, A., Hultqvist, A., and Johansson, B. Optical diagnostics of laser-induced and spark plug-assisted HCCI combustion, SAE paper 2005-01-0129, 2005.

5 Urushihara, T., Yamaguchi, K., Yoshizawa, K., and Itoh, T. A study of a gasoline-fueled compression ignition engine - expansion of the HCCI operation range using SI combustion as a trigger of compression ignition, SAE paper 2005-01-0180, 2005.

6 Wang, Z., Wang, J.-X., Sjuai, S.-J., and Ma, Q.-J. Effects of spark ignition and stratified charge on gasoline HCCI combustion with direct injection, SAE paper 2005-01-0137, 2005.

7 Perrson, H., Hultqvist, A., Johansson, B., and Remon, A. Investigation of the early flame development in spark assisted HCCI combustion using high speed chemiluminescence imaging, SAE paper 2007-01-0212, 2007.

8 Perrson, H. A., Johansson, B., and Remon, A. The effect of swirl on spark assist compression ignition (SACI), SAE paper 2007-01-1856, 2007.

9 Berntsson, A. W. and Denbratt, I. Optical study of HCCI combustion using NVO and an SI stratified charge, SAE paper 2007-01-012, 2007.

10 Pischinger, S. and Heywood, J. B. How heat loses to the spark plug electrodes affect flame kernel development in an SI-engine, SAE paper 900021, 1990.

11 Abraham, J., Bracco, F. V., and Reitz, R. D. Comparisons of computed and measured premixed charge engine combustion. Combust. and Flame, Vol. 60, 1985, 309-3223.
12 Reuss, D. and Sick, V. Spatial mixing, ignition and combustion inhomogeneities in HCCI combustion: An imaging study, SAE paper 2005-01-2122, 2005.

13 Miles, P. and Steeper, R. Private communication, Sandia National Laboratories, Combustion Research Facility, Livermore California, 2004.

14 Chang, J., Gralp, O., Filipi, Z., Assanis, D., Kuo, T.-W., Najt, P., and Rask, R. New heat transfer correlation for an HCCI engine derived from measurements of instantaneous surface heat flux, SAE paper 2004-01-2996, SP-1896, 2004.

15 Stivender, D. Development of a fuel-based mass emission measurement procedure, SAE technical paper 710604, 1971.

16 Gaydon, G. G. A. The spectroscopy of flames, 2nd edition, 1974 (Chapman and Hall Ltd, London).

17 Fansler, T. D., Drake, M. C., Stojkovic, B., and Rosalik, M. E. Local fuel concentration, ignition and combustion in a stratified-charge sparkignited direct-injection engine: Spectroscopic, imaging and pressure-based measurements, Int. J. Engine Res., 2003, 4(2), 61.

18 Maly, R. and Meinel, H. Determination of flow velocity, turbulence intensity, and length and time scales from gas discharge parameters, Proceedings of the Fifth International Symposium on Plasma Chemistry, Vol. ISSPC-5, pp. 552-557, 1981.

19 Maly, R., Meinel, H., and Wagner, E. Novel method for determining general flow parameters from conventional spark discharges, IMechE, Vol C67/ 83, pp. 27-32, 1983.

20 Hultqvist, A., Christensen, M., Johansson, B., Franke, A., Richter, M., and Alden, M. A study of the homogeneous charge compression ignition combustion process by chemiluminecence imaging, SAE paper 199-01-3680, 1999.

21 Sjoberg, M. and Dec, J. E. Combined effects of fueltype and engine speed on intake temperature requirements and completeness of bulk-gas reactions for HCCI combustion, SAE paper 2003-013173, 2003.

22 Farrell, J. T. and Bunting, B. G. Fuel composition effects at constant RON and MON in an HCCI engine operated with negative valve overlap, SAE paper 2006-01-3275, 2006.

\section{APPENDIX 1}

\section{Notation}

$A_{\text {flm }}$

$\mathrm{AF}$

ATDC after top dead-centre compression

CA

CATrans crank angle the combustion transitioned to CI, where $\mathrm{d}^{2} \mathrm{HRR} / \mathrm{dCA}^{2}$ is $\max$ 
CA10

CA50

CA90

CI

c.o.g.

$\mathrm{dV} / \mathrm{d} \tau_{\text {spk }}$

DI

Egap

$\mathrm{E}_{\mathrm{i}}$

EGR

EKG

EOCI

EOEkg,

EOFlm

EOI

EOSpk

EVC

EVO

Fmbf

HCCI

HRR

i.m.e.p.

$\mathrm{I}_{\mathrm{CN}}$

$I_{\text {flm }}$

$\mathrm{I}_{\mathrm{spk}}$

IVC

IVO

MAP

$\mathrm{MaxX}_{\mathrm{cog}}$

$\mathrm{P}_{\text {gap }}$

pdf

SACI

$\mathrm{SC}$

SI

SOSpk crank angle ATDC of 10 per cent mass-burned fraction

crank angle ATDC of 50 per cent

mass-burned fraction

crank angle ATDC of 90 per cent

mass-burned fraction

compression ignition

centre of gravity of the spark plasma

image area

voltage-decay rate

direct injection

total energy delivered to the spark

plug gap

total energy delivered to the spark

plug gap during the first image after spark breakdown

exhaust gas recirculation

early kernel growth

end of compression ignition $=$ CA90

crank angle at the end of EKG, where $\mathrm{d}^{2} \mathrm{~A}_{\mathrm{flm}} / \mathrm{dca}^{2}$ is max

end of flame period $=$ beginning of

CI, where $\mathrm{d}^{2} \mathrm{HRR} / \mathrm{dCA}^{2}$ is max

crank angle at the end of the injector command signal

end of spark discharge where

spark-discharge current returns to

zero

Exhaust valve closing CA ATDC

Exhaust valve opening CA ATDC

the final mass-burned fraction

homogeneous charge compression ignition

heat release rate, J/CA

indicated mean effective pressure

computed from IVC to EVO

Image intensity of the CN luminescence during the plasma discharge

average flame intensity in each frame spark-discharge current

intake valve closing CA ATDC

intake valve opening CA ATDC

manifold absolute pressure

maximum $\mathrm{X}_{\mathrm{cog}}$ achieved during an

individual cycle

total electrical power delivered to the spark-plug gap

probability density function

spark assisted compression ignition

stratified charge

spark ignition

start of spark discharge

$\begin{array}{ll}\mathrm{X}_{\operatorname{cog}} & \begin{array}{l}\text { distance from the centre of the } \\ \text { electrode to the two-dimensional } \\ \text { plasma-image centroid }\end{array} \\ \tau & \text { duration of the combustion period, } \\ \text { e.g. spark, EKG, flame, and CI } \\ \text { combustion. }\end{array}$

\section{APPENDIX 2}

\section{Processing of EKG and flame images}

The image-processing performed on the combustion-chemiluminescence images was performed according to the flow chart in Fig. Al. The processing above the dotted line was performed for noise rejection, and creates one 16-frame image for each of the 80 cycles recorded during a single 300 -cycle test. The main purpose of the mask is to reject light from noise outside the window field of view that would otherwise corrupt the flame area and spark c.o.g. measurements. It is also intended to minimize the reflected light, although achievement of this purpose is minimal and imperfect.

The image-processing functions below the dotted line in Fig. Al are applied to each frame of each cycle and the tabulated results used to compute the flame parameters noted in the main body of this manuscript. The first step is to binarize the previously discussed flame images using either a twocount threshold for computing EOEkg or a 3 per cent-of-max threshold for flame-area measurements (refer to the main text). The reason for and the implications of the two choices are demonstrated in Figs A2 and A3.

Figure A2(a) shows the complete flame image, with the red outline indicating the edge of the twocount binarized image; that is, every pixel inside the red outline would be given a value of 1 and counted as the flame area. In spite of the non-linear display scale used to enhance the low-intensity regions, there is a large black region in the early kernels (Fig. A2(a), frames 0-10) between the two-count edge and the blue contour $(\approx 25$ counts). This is an artefact of the display. In later frames (Fig. A2(a), frames 12-15), the chemiluminescence has high counts at the edge of the mask, and thus the binarized edge and flame edge appear the same. Figure A2(b) shows each flame image masked by the 3 per cent-of-max threshold, with the white line indicating the edge of the 3 per cent-of-max binarized region and the red line indicating the edge of the two-count binarized region. The white line is 


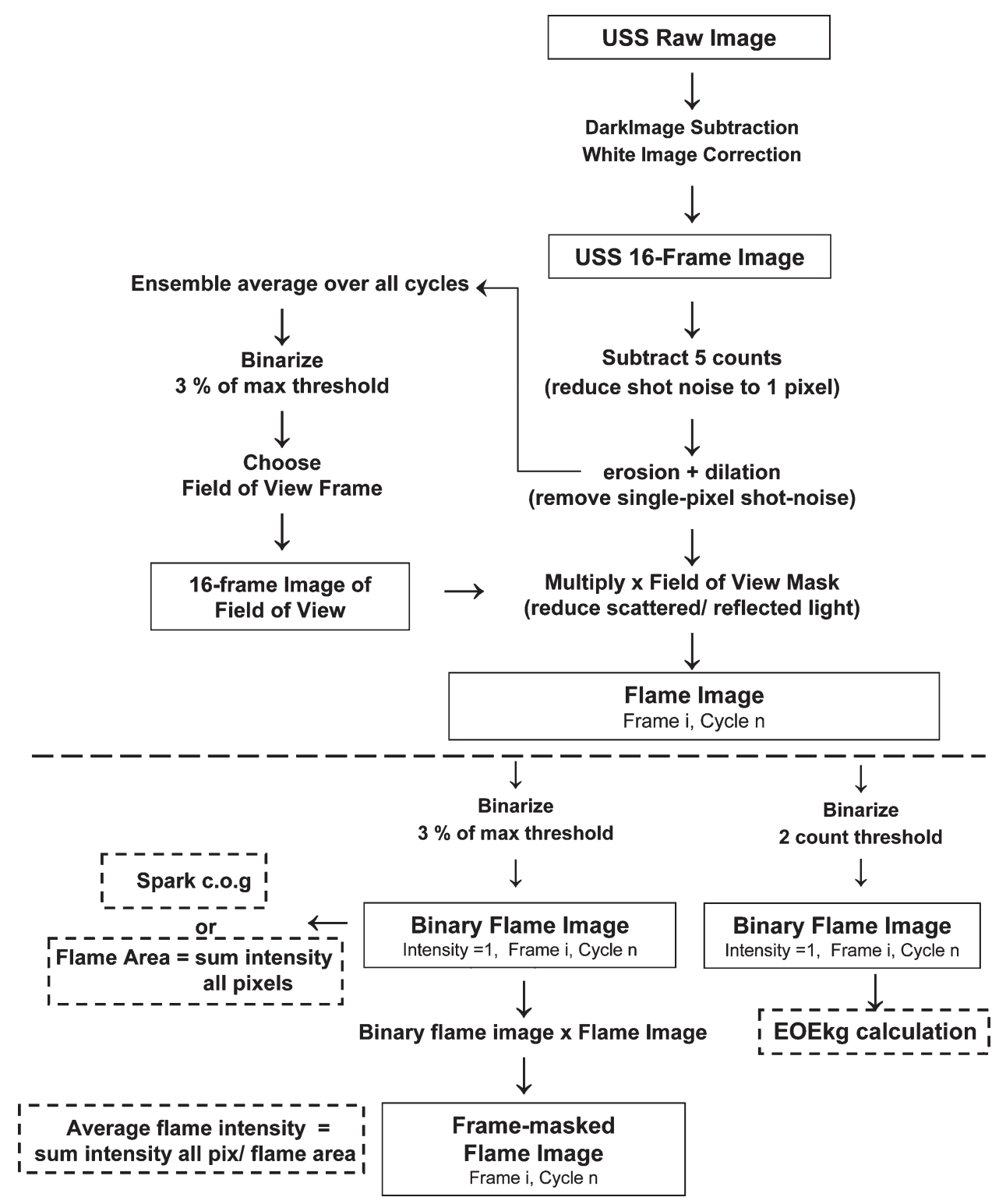

Fig. A1 Image processing functions. Functions above the dotted line were performed for noise rejection

not always visible where it coincides with highintensity flame chemiluminescence. However, Fig. A2(b) shows that the two thresholds are the same for the early kernels (frames 1-5). Then, as the flame image has higher intensity, the two-count threshold becomes coincident with the edge of the field-of-view mask (frames 8 and 9) while the 3 per cent threshold remains smaller. In fact, if the flame intensity grows faster than the flame area, the area of the 3 per centof-max binary image can actually decrease as it does between frames 8 and 9 . This is shown more clearly in Fig. A3(a). The most probable reason for the discrepancy between the two threshold areas is that, as the flame intensity increases, the background scattering is above two counts. It is, of course, possible that low-temperature reactions due to compression also contribute, although these measurements cannot distinguish between the two.

In this study the two-count threshold was used to indicate when the early kernel transitions to a flame, EOEkg, to avoid the maximum-second-derivative ambiguity caused by the decrease in area of the 3 per cent-of-max threshold (refer to Fig. A3(a)). The 3 per cent-of-max threshold was considered to be a more intuitively correct measure of the flame as it essentially is a variable-intensity background subtraction. Thus, the 3 per cent-of-max threshold is used to generate the conditionally sampled flamearea growth plots (Fig. 16) with the expectation that averaging will filter out the few errant cycles. 

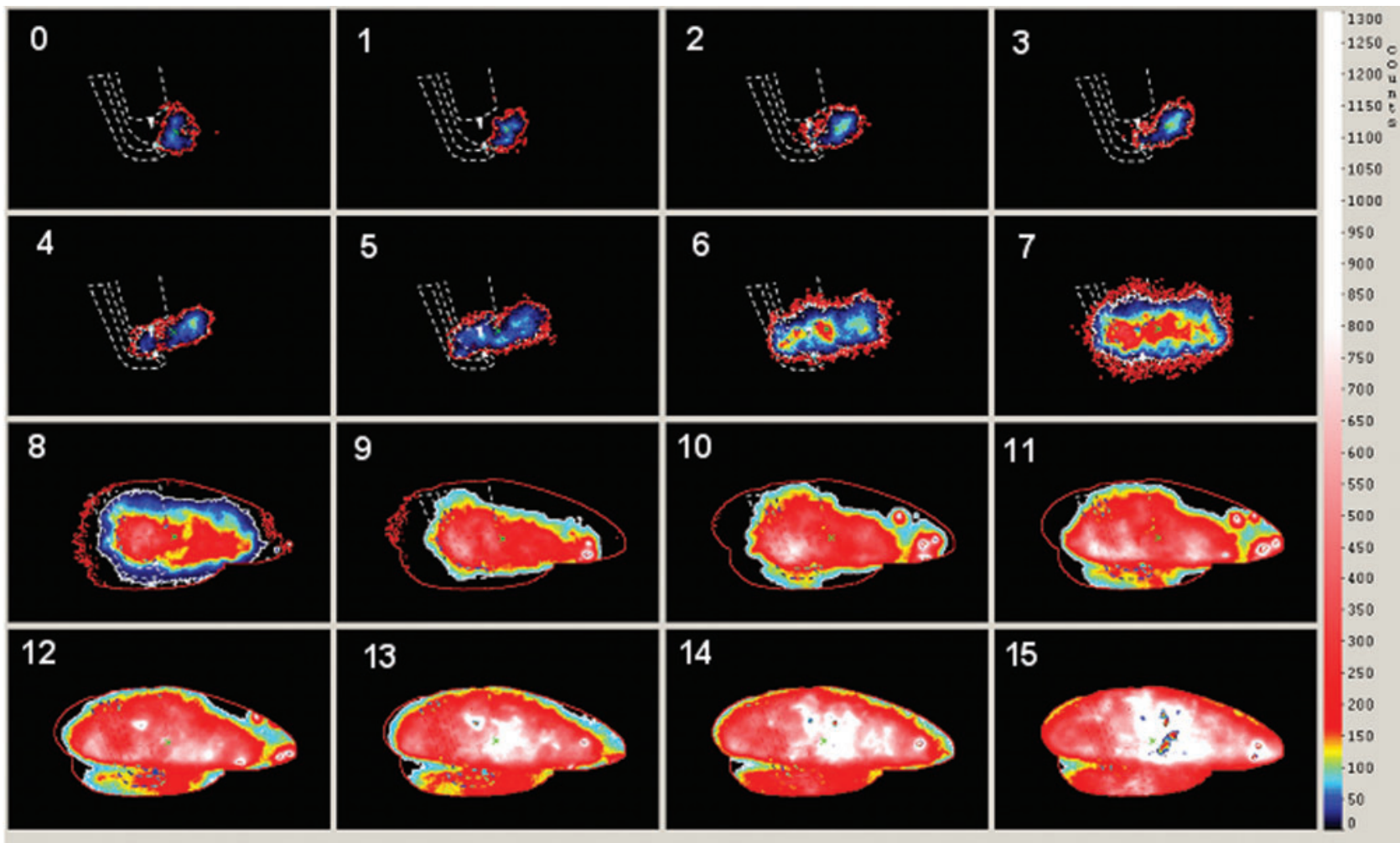

Fig. A2 Binarization threshold strategies comparing the image intensities with the edge of the two-count-threshold binary region (red line) and the edge of the 3 per cent- thresholdbinary region (white line)

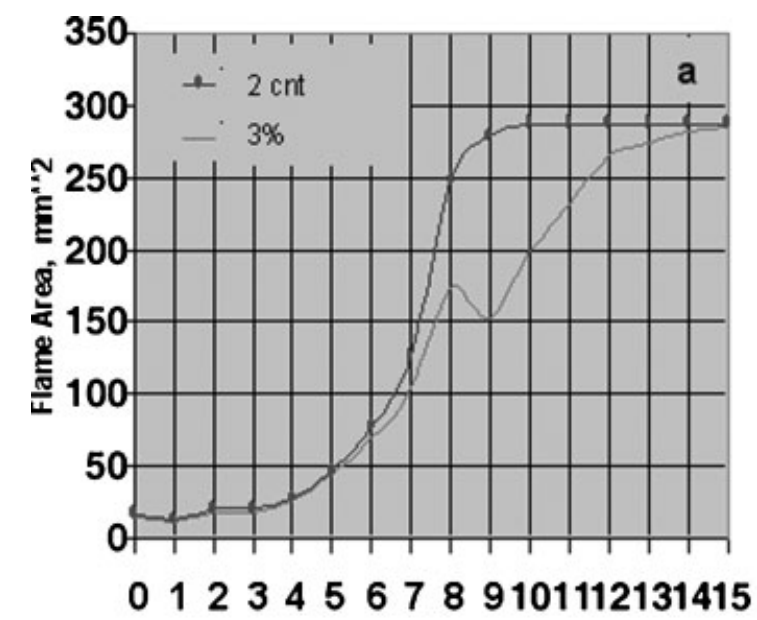

\section{Frame Number}

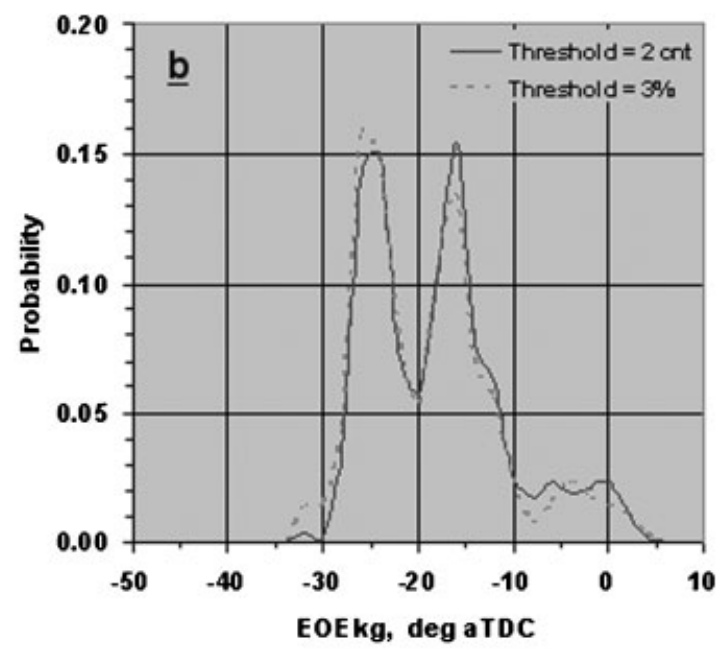

Fig. A3 Comparison of (a) two-count and 3 per cent-of-maximum thresholds strategies on flame area for the images in Fig. A2, and (b) the effect on the EOEkg pdf for all 300 cycles

Fig. A3(b) shows that the pdf of the EOEkg (for the imaged 480 cycles) is qualitatively unchanged. Thus it is concluded that the observations and conclusions in this paper are unaffected by the choice. 